
2

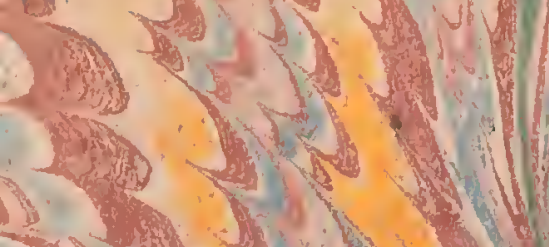

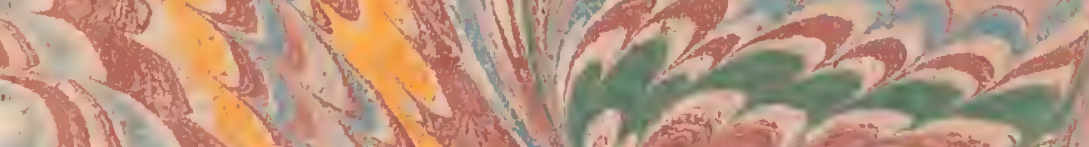

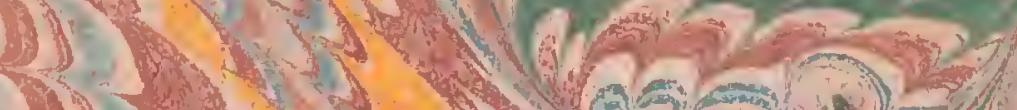

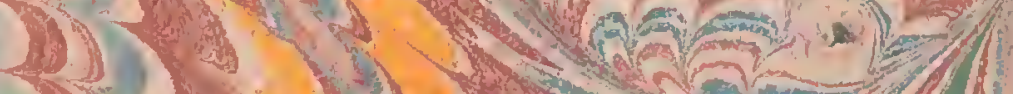

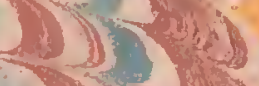

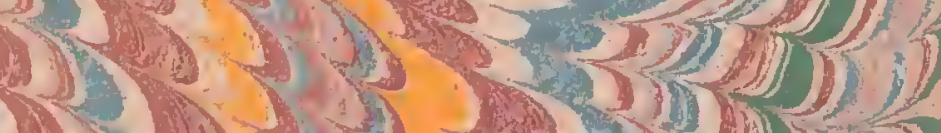

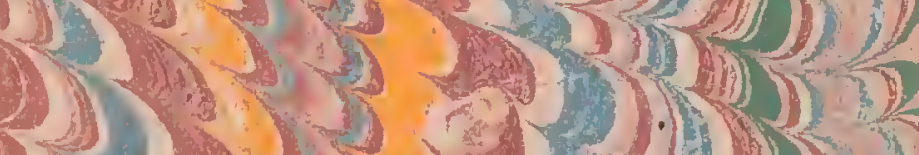
15)

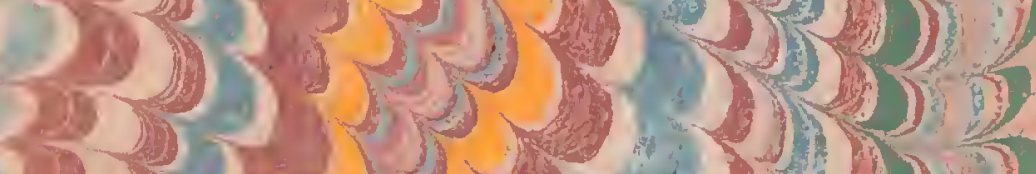

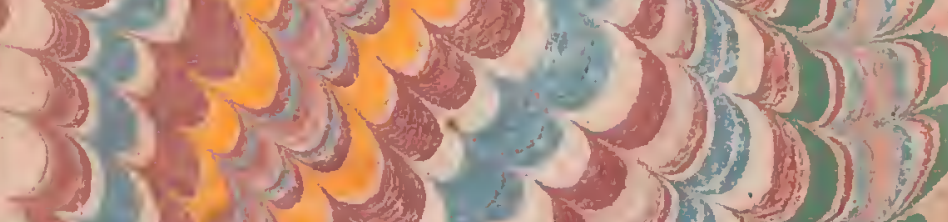

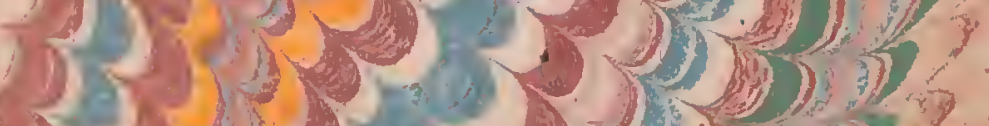

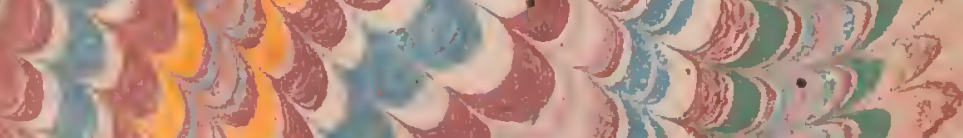

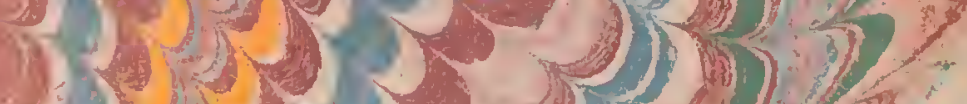
(1)

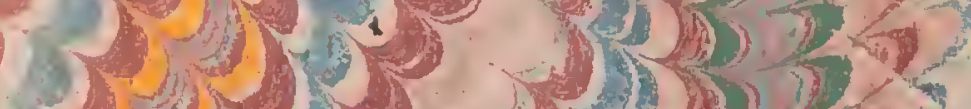

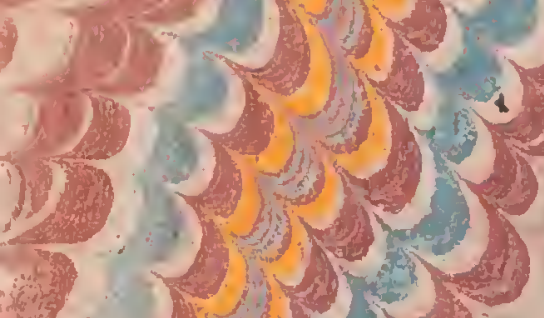
if (6)

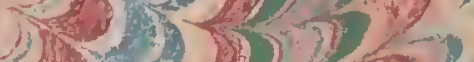

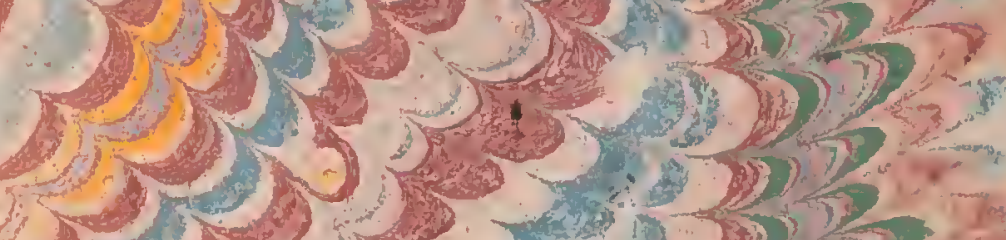
2.

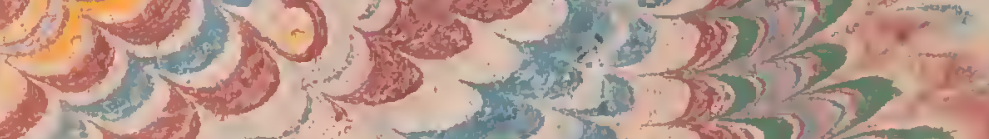

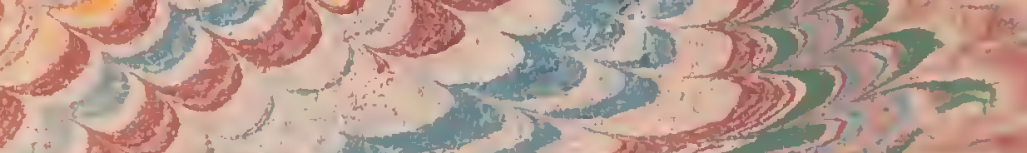


Lasoiser 

2 owenges.

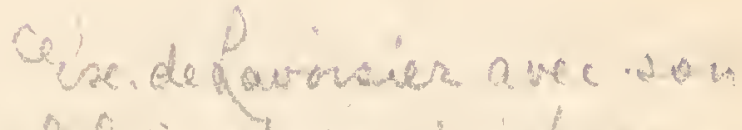

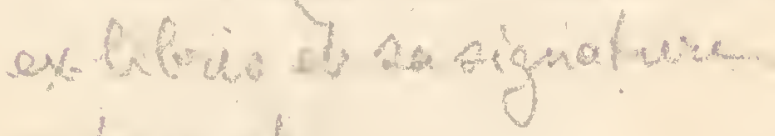
autoyespots

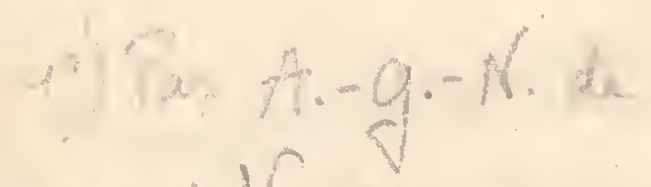

Thance de Vaugencil.

25y Pa: harquate

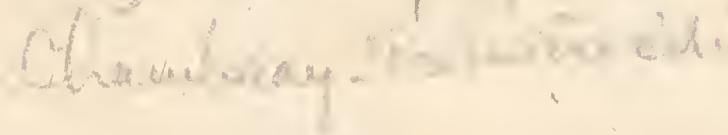




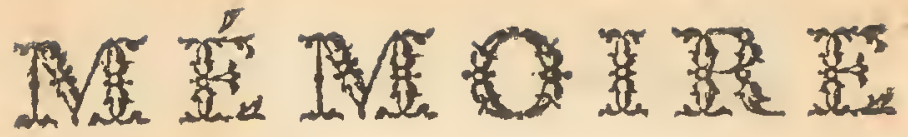

\section{SUR LA CULTURE}

DUY SA

E T

\section{SES AVANTAGES}

\section{A N}

\section{IA HAUTE CHAMPAGNE;}

Par $M_{0}{ }^{*}{ }^{*}$ de la Sociéé Littéraire de Chaa-:

Lons, Afocié correspondant de l'Académie Royale des Sciences \& Arts de Metro

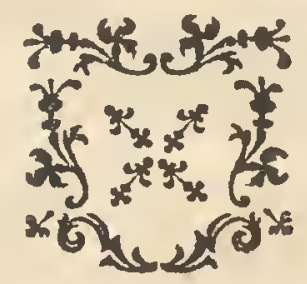

$A M S T E R D A M$.

M. D C C. L X I V. 


$$
\begin{aligned}
& \text { Lavoisin } \\
& 513 \\
& 207 \\
& 513 F 81
\end{aligned}
$$




\section{AUX LABOUREURS.}

M Es AMIS\& MES FRERES, c'eft pour vous quej'écris. Le defir de contribuer à votre bonheur m'a dictéle Mémoire que je yous adreffe Sur la Culture du Sain-Foin. Ce ne font point des nouveautés que je vous propose, je ne fais que yous retracer les ancicnnes pratiques de nos Peres. Les Ecrivains qui nous ont laiffé des régles fur I'Agriculture, il $y$ a plus de deux cens ans, nous parlent des Prairies Artificielles en Luferne, en Treffle \& en Sain-Foin. Cette dernière eft celle qu'il convient le mieux d'établir dans la haute Champagne, \& les différentes épreuves que j'en ai faites, m'ont mis en état de yous détailler cetze Culture dans tous fes points, $\mathcal{E}^{\circ}$ les avantages qui en doivent ré- 


\section{iv AUX LABOUR EURS:}

fulter. Vous ferez convaincus de tous ces avantages, $f i$ vous lifer cet $E$ crit avec attention, Eilvoús engagera fans doute à vous les procurer. La protection que le Gouyernement accorde aujourd'hui da l'Agriculture, eft un motif qui doit vous animer à Jortir de l'état de langueur dans lequel vous étiez tombés. On connoît toute l'importance de la culture des terres, E combien ceux qui s'en occupent véritablement, ont droit à l'eftime publique. $L$ a profeffion de $L a-$ boureur eft honorable, il faut la rendre utile; vous $y$ parviendre en fuivant ce que je yous propofe.

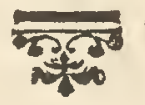



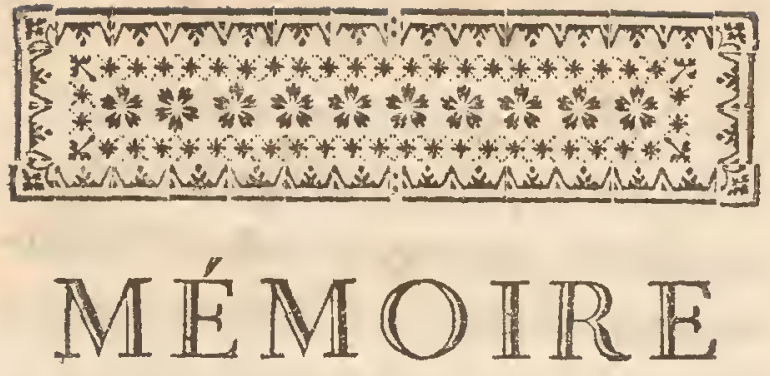

SUR LA CULTURE

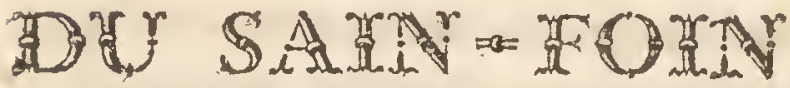 D A N S}

LA PROVINCE

$D E C H A M P A G N E$.

号Es excellens Écrits qui ont paru. depuis plufieurs années furl'Agriculture, en ranimant le goût du Public pour un Art auffi important qu'il étoit négligé, a fans doute éclairé un grand nombre de Cultivateurs, \& déja plufieurs Provinces voient renaitre l'émulation dans leurs campagnes, \& la terre fe prêter aux tuavaux réfléchis de gens qui s'honorent aujou: 
2

d'hui du foin de la cultiver.

La Champagne profitera moins de ces fecours qu'aucune autre Province. Son fol eft d'une nature particulière qui lui eft propre, \& anquel on ne peut pas appliquer avec le même avantage. les différentes méthodes qui peuvent s'exercer utilement fur les autres natures de terre.

L'induftrieux Auteur du Traité; intitulé:Prairies Arificielles pour la Province de Champagne, a cependant rendu un fervice effentiel à fa $\mathrm{Pa}$ trie en y introduifant la culture du Sain-Foin. Il eft certain que jufqu'à préfent on n'a rien trouvé de plus propre pour fertilifer les terres de Champagne, qui ne connoiffent encore d'autre véritable amendement que le fumier.

L'abondance du fourage, en nourriffant une plus grande quantité de 
Beftiaux, peut fenle fournir une grande quantité de funiers; ainfi le réfultat de la culture du Sain-Foin eft clair, \& fon utilité démontrée.

Mais, comme l'a remarqué l'Auteur de l'E Jai fur l'amélioration des terres, la méthode décrite dans le Traité des Prairies Artificielles eft longue; \& tandis que les autres Provinces feront des progrès rapides avec les fecours multipliés qu'o leur préfente de toutes parts, celle de Champagne n'avancera qu'à pas lents, \& ce retard ne peut que lui être préjudiciable.

C'eft dans la vue d'accélérer fes progrès qu'on fe détermine à mettre ce Mémoire au jour. Il n'eft que le réfultat de diverfes expériences faites pendant fept années, \& l'on n'y avance rien qui ne foit juftifé par les faits. 


\section{4

On commencera d'abord par ex poler les différentes méthodes que l'on a fuivies pour fe procurer promptement une Prairie Artificielle en Sain-Foin. On examinera enfuite les avantages de cet établiffement; \& dans les détails de cette difcuffion, on décrira les différens procédés pour bien faire cette culture, quie l'on fuivra jufqu'au défrichement.

Des moyens pratiqués pour $\int e$ procurer promptement une Prairie Artificielle.

L'USAGE en Champagne eft de femer les Fromens fur le fumier. On feme enfuite de l'Orge, auquel fuccédent alternativement le Seigle \& l'Avoine, jufqu'à ce que la terre épuifée reçoive de nouveaux fumiers.

L'objet effentiel étoit d'avoir 


$$
\text { DU SAIN-FOIN. }
$$

promptement une quantité de SainFoin fuffifante pour pouvoir augmenter le nombre des Befiaux; \& lon a cru devoir, fans s'arrêter à aucun ordre, mettre indifféremment en prés artificiels tout ce qui pouvoit fe trouver de terre fufceptible de cette converfion.

En conféquence, toutes les terres qui venoient de porter du Froment ont été enfemencées avec du SainFoin \& de l'Orge; \& toutes celles qui venoient de porter de l'Orge, l'ont été avec du Sain-Foin \& de l'Avoine.

On woit que ces Sain-Foins ont été femés au Printemps, ils ont parfaitement réuffi, ils ont reçu les atteintes de la faux lorfqu'on a abattu les grains, \& au mois de Mai fuivant ils ont donné la première récolte.

Il eft vrai qu'on s'eft privé par-là 
d'une première récolte de Seigle fur des terres nouvellement funées, qui auroit dî être abondante; mais, outre qu'il n'eft pas poffible de changèr tout d'un coup un fyftême de culture fans qu'il en réfulte un dérangement paffager, on ne craint point d'avancer qu'on n'en a fouffert alscun préjudice; \& c'eft ce qui fera prouvé dans la fuite de ce Mémoire, où l'on détaillera les avantages de la culture du Sain-Foin.

11 eft évident qu'il n'y a point de façon plus prompte de fe procurer tout d'un coup une Prairie Artificielle; mais la plîpart des Laboureurs efrrayés du facrifice qu'il faudroit faire de leurs meilleures terres à l'établiffement d'un herbage dont iils n'ont pas encore médité toute l'importance, rejettera fans doute ce procédé. La privation de plufieurs 


$$
D U S A I N=F O I N \text {. }
$$

récoltes de grains fur des terres qui ne leur rapporteront que du fourage pendant quatre à cinq années, fera toujours une pierre d'achopement qui les arrêtera.

C'eft pour parer à cet inconvénient que l'on a cherché d'autres moyens pour établir promptement des Sain-Foins fans y employer les terres nouvellement fumées.

Il eft généralement connu, que les végétaux enfouis améliorent la terre. Le Sarafin eft une plante des plus propres à cet ufage, parce qu'il jette une quantité de rameaux qui font remplis de fucs lorfqu'il entre en fleur. C'eft alors \& avant que le grain foit formé, qu'il faut l'enterrer à la charrue. La terre fe trouvera fuffifamment améliorée pour recevoir du Sain-Foin, fur tout fi lon obferve exactement le procédé qu'on va décrire. 
8

Il faut dans le courant de l'hiver donner un premier labour à la terre qu'on deftine à mettre en prairie; au mois de Février ou au commencement de Mars, on donne le fecond plus profond que le premier; \& enfin le troifiéme vers le 15 ou le 20 du mois d'Avril, plus profond encore que le précédent; car il eft important pour le Sain-Foin que la terre foit remuée à une grande profondeur : on en dira les raifons. Après ce dernier labour, la terre étant herfée \& roulée, on femera le Sarafin à raifon de quatre boiffeaux par journal *,$\&$ on l'enterrera à la herfe. Les plantes ne tarderont pas à paroître, \& poufferont avec d'autant plus de vigueur, que la terre aura été bien préparée. Lorfque

* Le journal dont on parle, eft de dix denrées, \& contient sS5S3 pieds quarés. 


\section{$D U S A I N-F O I N$.}

ces plantes abonderont en fleurs, fi elles font trop fortes \& trop vigoureufes, il faudra les faucher \& les tirer dans la roye comme on fait les fumiers, pour les enfouir à la charrue. Si on peut les enfonir fur pied fans être obligé de les faucher, ce fera de la peine d'épargnée. On eft parvenu à en enterrer de cette fatçon, qui étoient de la plus grande force. Cette opération bien faite, $\&$ toutes les plantes bien recouvertes, on peut au bout de huit à dix jours femer le Sain-Foin \& paffer deffus la herfe à reculons, il fera fuffifamment recouvert. C'eft alors que s'opére la décompofition du Sarafin, \& que fon adion a plus de force pour faire lever promptement le Sain. Foin. Cependant fi les travaux de la moiffon ou d'autres empềchemens ne permettoient pas de faire cette 
femaille dans le mois d'Août, il fatt droit la différer au Printemps, parce qu'il eft effentiel que le Sain-Foin puiffe avoir le temps de pouffer des racines affez profondes pour réfifter aux gelées qui viennent quelquefois dès le mois de Septembre. Ce retard exigeroit un nouveau labour en Février, \& le labour pour la fe. maille.

F.n 1750, on enfemença ainfs aut mois d'Avril trois journeaux \& demi de très-mauvaife terre en Sain-Foin, fur des Sarafins enfouis au mois de Septembre précédent. Cette terre étoit tellement épuifée, que le Sarafin y vint mal, il y avoit même des places confidérables où les plantes n'avoient pu fubfifter. Ce qui y fut renfermé fut fuffifant pour améiiorer le fol au point de produire de beau Sain-Foin; il fubfifte encore \& n'a 


\section{DU SAIN-FOIN.}

point dégénéré. Cependant on ne cite cet exemple que pour faire voir jufqu'oì peut aller l'effet du Sarafin enfoui, même en petite quantité. On avoit choifi exprès un très-mauvais terrein, fur lequel il n'étoit plus poffible de faire venir dn Seigle; le Sain-Foin y avoit été femé feul, on n'avoit pas eu affez de confiance au fol pour joindre de l'Avoine au SainFoin; on vouloit voir d'ailleurs, fi ce dernier femé feul en Printemps réfifteroit aux chaleurs de l'été: elles furent vives en 1759. On a eu pleine fatisfaction à tous égards. Malgré cette épreuve, il fera toujours prudent de ne pas prendre une terre auffi dépourvue de principes nutritifs pour $y$ mettre du Sain-Foin. On fe trouvera toujours mieux de prendre une terre médiocre.

La méthode qu'on propofe n'eft 
pas difpendieufe; le Sarafin eft une graine qui ne coûte pas cher, dix. fols le boirfeau eft le plus haut prix qu'elle fe vende dans le courant de l'année. Ainfi pour quarante fols, on peut mettre un journal en étát d'être enfemencé en Sain-Foin. Quelle différence, s'il falloit y mettre du fumier, qui dans ce pays en évalué jufqu'à trois livres la voiture.

Mais lẹs hommes font inconféquens, le préfent feulles touche. Le Sarafin definé, lors de la femaille à l'amélioration du fol, change de defination lorfqu'il eft en fleur; l'apas d'une récolte prochaine le garantit de la faux jufqu'à la maturité du grain, \& le but eft manqué. C'eft ce qu'on a vu arriver plufieurs fois.

Les Vefces \& les Navettes enfouies dans le temps de la fleur feront le même effet que le Sarafin; c'eft a 


\section{DU SAIN-FOIN.}

haque Laboureur à choifir celui de ces trois verdages qu'il préfere d'employer à la préparation de la terre qu'il fe détermine de mettre en Sain. Foin.

La nécelfité de ces établiffemens dans chaque ferme dépourvue de Prairies naturelles, eft fuffifamment démontrée, il feroit inutile d'y infifter. Mais comme tous les avantages qui ẹn réfultent ne font pas également connus, qu'il en eft même contre lệquels le préjugé a prévalu, on a cru néceffaire de les expofer tous dans cet Ecrit ; afin que réunis fous un feul point de vue, ils puifient frapper lés Cultivateurs \& les déterminer par celle de leur intérêt à adopter une pratique capable de leur procurer une aifance dont jufqu'à préfent ils n'ont pu fe flatter.

C'eft ce qu'on ya faire dans la fuite 
de ce Mémoire, où l'on confidérera le Sain-Foin, $\mathrm{I}^{\circ}$. Comme objet de culture $; 2^{\circ}$. Comme fourage \& pâture; $3^{\circ}$. Comme denrée commerçable $; 4^{\circ}$. On parlera de la façon de le défricher utilement.

Tous ces détails, qui ne feront que le réfultat d'une fuite d'expériences, un réfumé de faits, feront une nouvelle démonftration de la néceffité d'étendre la culture du Sain-Foin dans toute la haute Champagne.

\section{De la Culture duSain-Foin.}

LA meilleure \& la plus effentielle préparation à donner aux terres, eft de les bien labourer. Lesfols crayeux ne différent de la nature des autres fols pour les labours qui leur con'viennent, qu'à quelques égards qu'il eft important d'obferver.

Ils fe divifent en trois efpéces prin- 


\section{$D U S A I N-F O I N$.}

cipales qui font la craie dure, qui eft un mêlange de pierre, de craie $8 x$ de terre végétale.

La craie molle \& friable qui eft incorporée avec la terre végétale.

Et la grève qui n'eft aufí qu'une craie modifiée reffemblante à l'extérieur à du fable 'de rivière, mélangée auffi avec de la terre végétale.

La première efpece n'a communément que fix à feptpouces de fonds, au-deflous duquel la craie abonde. Cette efpece veut être labourée légèrement, parce qu'en approfondiffant trop, on ramenercit la craie pure fur la furface. Mais elle le veut être fouvent, parce que moins elle a de fonds, \& plos elle a befoin d'être expofée forivent à láir, au foleil $\&$ aux autres influences, pour recevoir dans toutes fes parties les principes de la végétation. 
La feconde efpece au contraire " veut être labourée profondément pour en expofer une plus grande quantité au bénéfice de l'athmofphere. Et comme cette efpece eft natu. rellement fort legère, les influences de l'air la pénétrent plus facilement. Mais par la raifon de fa legéreté, elle ne veut pas être fi fouvent labourée, parce qu'elle n'auroit plus alors affez de confiftence, \& que les plantes auroient de la peine à s'y foutenir.

La troifiéme efpece veut être labourée profondément \& plus fouvent que la feconde, parce qu'étant brûlante de fa nature, $\&$ d'ailleurs fujette à s'affaiffer \& à fe comprimer, elle a befoin d'être rafraîchie \& divifée plus fouvent.

Yoilà à peu près, ce que l'on peut dire en général des fols crayeux de 
la haute Champagne, \& de la facon dont il faut les labourer; mais comme ils fe fubdivifent encore en beaucoup d'efpeces particulières, c'eft à chacun à connồtre celui qu'il cultive, \& à partir des principes qu'on lui indique, pour regler les labours qu'il convient de lui donner.

Cependant l'ufage général des La* boureurs de cet Province, eft de ne labourer que rarement, \& de n'entamer que la fiperficie. Ufage qui n'eft fondé fur aucun principe, ou plutôt qui efl contre tout principe, - qu qui trompe fouvent leurs efpéran. ces.' L'abandon de cette mauvaife pratique eft abfolument néceffaire pour la culture du Sain-Foin, qui veut être ferné dans une terre ameublie, à une profondeur convenable, pour que la jeune racine qui fe détermine tonjours en plongeant, trou- 


\section{8}

ve dans les premiers temps de fit. croiflance une terre facile à pénétrer. Une fois parvenue au fond du fillon, elle aura déja acquis affez de force pour sintroduire dans la terre ferme, pour sinfinuer entre les craies \& aller chercher fa nourriture à une grande profondeur, fans rien prendre, ou bien peu de chofe, à la terre de furface, qui pendant cinq années que le Sain-Foin la couvre, s'enrichit dans le repos $\mathbb{L}$ a fraîcheur que l'herbage y retient la pénétre, le travail des récoltes la rafermit, les feuilles qui fe détachent y pourriffent, \& après le défrichement, les plantes \& leurs racines retournées y dépofent un nonvel engrais. Ainfi après la deftruction de la prairie le fol fe trouve renouvellé, amélioré \& propreà porter du Froment.

Quoiqu'il foit reconnu que les 


\section{$D U S A I N-F O I N$.}

terres rouges font les plus propres pour la culture du Sain-Foin, cette préférence, fondée fur ce que cette efpece de fol a plus de profondeur, n'eft pas une exclufion pour lés autres. On pent affurer, d'après l'expérience, qu"il vient très-bien furles terres grifes \& fur les terres blanches. On en a femé fur toutes ces efpeces de fols, \& il y eft très bien venu.

On en a vu croître $\&$ profiter dans des foffés creufés à plufieurs pieds dans le crayon; la graine étoit tombée dans le fond entre des pierrailles de craie, les racines avoient trouvé dans les petits intervalles affez de terre pour y plonger \& s'y nourrir.

On en fema avec de l'Orge au' mois d'Avril I762, au mois de Mai fuivant, il furvint un orage furieux, les eaux prirent leur écoulement au milieu du champ, \& la violence du 
torrent dégrada le fol, enleva les plantes d'Orge. Celles de Sain-Foin réfiftèrent. Dans l'efpace de moins de fix femaines, à compter des femailles, leurs racines avoient déja pénétré aì fond du labour, \& s'étoient infinuées entre les pierrailles. Elles fubliftent à préfent * \& font fortes \& vigoureufes.

Ces expériences qui prouvent que le Sain-Foin peut venir fur le plus mauvais terrein, démontrent en même temps, ce qu'on a dit plus haut, qu'il tire fa nourriture du' fond fans prendre que bien peu de chole de la furface. On feroit prefque tenté de regarder cette plante comme naturelle en Champagne. On en trouve fur des termes fort éloignés des champs oì on la cultive. En fuppo-

* Fa Norembre 8763 。 


\section{DU SAIN.FOIN: $2 I$}

fant que ce font des graines que le vent $y$ a tranfportées, ou qui y ont été jettées par quelqu'autre hazard; il ne s'enfuit pas moins qu'il faut que cette plante foit bien analogue au terrein, puifque des graines jettées fur l'herbe \& fur la mouffe fans aucune culture, y prennent racine \& s'y maintiennent. Cet indice eft comme un averiffement de la Nature qui nous convie à cultiver une plante faite pour le pays, pour nous dédommager des prés naturels qu'elle lui refufe. Sa culture fubfitueroit l'abondance à la férilité.

Si le Sain-Foin peut être femé fur routes les efpeces de fols de la Champagne, il peut l'être auffí dans toutes les faifons \& avec tontes fortes d'autresgraines. On en a femé en Mars avec de l'Avoine, en Avril avec de l'Orge, en Mai avec du Sarafin, en 
Août avec du Seigle, il a toujours réuffi. Mais il paroît que la meilleure méthode eft de le femer feul à la fin d'Août. On y gagne, en ce que la plante ayant joui toute feule d'une nourriture qu'elle eût été obligée de partager avec d'autres, fait des progrès plus rapides, \& dès le Printemps fuivant elle fe trouve en état. de donner une première dépouille honnête.

Cecin'infirme pas ce qu'on a avancé, que le Sain-Foin va chercher fa nourriture dans la profondeur du fol, fi l'on fait artention, que la graine femée fur la furface \& enterrée à la herfe, y prend fa première croiffance, que fa racine s'y forme, \& qu'il faut qu'elle la traverfe avant de s'infinuer dans l'intérieur.

Aufurplus, ce qui femble arrêter la plîpart des Laboureurs, c'eft qu'ils 
fe perfuadent que le Sain-Foin veut être femé dans une terre chargée d'engrais, ce qui les priveroit, ainfi qu'on l'a remarqué au commencement de cet Ecrit, d'une fuite de récoltes en grains. L'obfervation eft importante. Mais on n'exige point d'eux de fi grands facrifices : voici encore un nouveau moyen de leurs conferver leurs fumiers \& leurs récoltes ordinaires.

Le Sain-Foin peut fe paffer de fitmier; il ne s'en trouve point dans l'intérieur du fol d'oin il tire principalement fa fubfifance. 11 n'eft queftion cue de pourvoir à fes befoins pendant fon enfance, \& c'eft ce qu'on fait par le moyen des labours.

On leur confeille donc de faire choix dans leurs terres les plus éloignées, de celles qu'ils ne cultivent point, ou qu'ils ne cultivent qu'à 
pérte. On leur confeille, dis-je, de choirir celles qui ont le plus de fond, de les labourer au commencement de l'Automne, aurf profondément qu'il fera pofible, de pafer même la charrue deux fois dans la même roye afin d'aprofondir jufqu'à neuf à dix pouces, \& de répéter ce double labour dans le courant de No. vembre. La terre fera ainfi préparée pour recevoir toutes les influences de lair, \& fe chargera pendant l'hiver d'une abondance de fubffance fuffifante pour la nourriture du Sain-Foin. Cette opération qui fe fait après celle des femailles des gros grains, ne prend rien fur leurs travaux ordinaires. Au Printemps fuivant, ils peuvent femer le Sain. Foin avec de l'Avoine ou du Sarafin; ou sils veulent mieux faire, ils attendront à l'Automne, Les labours, 


\section{$D U S A I N-F O I N \cdot 25$}

que ce retard les engagera à multiplier, tourneront à l'avantage du Sain-Foin, qui doit être femé fur un léger labour \& enterré à la herfe. Ils fe garderont bien de faire marcher le rouleau, ni même le dos de la herfe pour applanir le terrein avant que tout le Sain-Foin foit levé; parce que fa feuille féminale étant de forme arondie, elle ne pourroit percer un terrein comprimé, fur tout s'il furvenoit de la pluie après l'opération. Mais quand toutes les plantes feront forties de terre, cette opération fe fera utilement par un temps fec, principalement pour rafermir \& donner de la confiftence au fol.

\section{Du Sain-Foin confldéré comme Fourage $E$ Pature.}

APRES avoir expofé les avantages 
du Sain-Foin quant à la culture, il n'eft pas moins intéreffant de décrire ceux que l'on retire de fon ufage.

Le premier \& le plus effentiel eft de s'approvifionner d'une bonne $\&$ abondante nourriture pour tous les animaux de la bafle-cour, que l'on nourritavec du Foin, \& de fe mettre en état d'en augmenter le nombre au grand bénéfice de la.Ferme.

Le temps le plus convenable pour faucher le Sain-Foin, eft lorfqu'il eft en pleine fleur. Les rameaux des plantes font tendres \& fucculents; lorfqu'il eft fané avec attention \& à propos, toute cette fleur:y refte; il eft fin, délicat $\&$ favoureux, les chevaux \& les beftiaux le mangent avec délices.

La'Plûpart des Laboureurs attendent pour le couper qu'il foit tontà-fait en graine, parce que jufques- 


$$
\text { DU SAIN-FOIN. }
$$

là il prend toujours quelqu'accroiffement, ce qui augmente un peu la quantité. On convient même qu'iI peut être un peu plus nourriffant pour des chevaux de travail; mais ils ne penfent pas qu'ils fe privent par-là d'une feconde coupe qui eft toujours importante quand il fur- vient de la pluie, qui fait promptement reverdir la Prairie, \& qui furpaffe auffi toujours dans les années de féchereffe'la petite augmentation qu'ils auroient ménagée en différant le premier fauchage. Or ce bénéfice eft entièrement perdu quand ils le font trop tard, parce que ne pouvant faire le fecond que dans l'arrière faifon, le foleil n'a plus afiez de force, \& ne refte plus affez longtemps furl'horifon pour faner promptement. Les pluies furviennent \& le Foin eft perdu avec le temps \& la 


\section{$28 \quad C \quad U L L T U R E$}

peine. Perte d'autant plus confidérable, que l'expérience apprend que le regain eft le fourage fec qui convient le mieux aux vaches; il entretient l'abondance du lait; le SainFoin de la premiere coupe au contraire le tarit.

D'autres encore plus mal avifés, guidés par un faux principe d'intérêt, ne fe contentent pas de laiffer monter le Sain-Foin en graine, ils attendent qu'elle foit meure, ils la détachent de la plante, \& croyent nourrir leurs chevaux avec la paille qui refte. S'ils fçavoient combien ils s'y trompent à leur défavantage, ils changeroient bien-tôt de méthode. Ne voyent-ils pas que toute plante qui a porté fon fruit jufqu'à parfaite maturité s'eft épuifée au point de fe défécher. D'ailleurs le SainFoin ayant fouvent perdit toutes res 


\section{$D U S A I N-F O I N$.}

feuilles dans l'opération de l'extraction de la graine, il ne refte plus que des bâtons. Quelle fubftance peut avoir une tige déféchée pour alimenter des animaux qui ont befoin d'une nourriture forte \& fucculente. lls croyent avoir beaucoup gagné, parce qu'ils ont recueilli une graine de défaite qui leur procure quelque argent. Mais ils ne penfent pas que leurs chevaux mal nourris dépérifient, perdent de leur valeur \& n'ont plus la même vigueur nile même courage, pour faire bien \& promptement les travaux anxquels ils les emploient. Ils the penfént pas que leurs Vaches ne jettent que des Veaux miférables qu'elles n'ont pas, la force de nourrir, que la laiterie ne rend rien, que les fumiers ne font ni bien conditionnés ni abondans, \& que les profits de l'étable. 


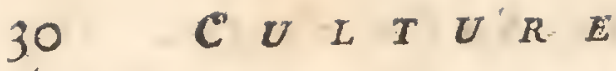

font réduits à très-peu de chofe. Ainfi ce quils gagnent par le prix. qu'ils retirent de leur graine, ne peut faire compenfation avec ce qu'ils perdent par la mauvaife qualité de leur fourage,

Cependant il y auroit du ridicule à profcrire de leurs récoltes la graine de Sain-Foin, à prêclier l'établiffement des Prairies Artificielles \& i en ôter les moyens. Ils fe trouvent naturellement ces moyens dans la. pratique di fauchage, lorfque le Sain-Foin eft en fleur. Après cette première coupe, les plantes ne tardent pas à réparer les pertes qu'elles ont faites, elles fe hâtent de reproduire de nouvelles fleurs qui fourniffent de la graine, \& c'eft celle-la qu'un Cultivateur intelligent doit recueillir. On ne lui reprocheroit cependant pas sil avoit une 


\section{DU SAIN-FOIN. 3 I}

Prairie plus que fuffifante pour l'ap. provifionnement de fa grange, d'en mettre un canton en réferve pour recuẹillir la graine de la première faifon. On convient qu'elle fournit davantage que la feconde, \& cette précaution feroit fage.

Il y a plufieurs façons de faire cette récolte. Les uns fauchent le Sain-Foin, l'enlèvent quand il eft fec $\&$ le battent dans la grange. Les autres fe tranfportent fur le champ \& égrappent fur pied les graines que les plantes leur offrent. D'autres enfin font faucher le Sain-Foin comme l'Avoine aver la faux garnie de crochets; le matin, à la rof́e, ils le ramafient en petites bottes avec des rateaux ou fauchets, (ouvrage qu"il faut ceffer auffi-tôt que le foleil cornmence à fécher la terre) fur les dix heures du matin ils fe tranfpor- 
tent fur le champ, y étendent des draps, prennent d'une main une poignée de Sain-Foin, \& avec une baguette ils frappent legérement de l'autre fur le bout de la poignée qui préfente la graine, qui céde au moindre effort $\&$ tombe fur les draps. Les Batteurs jettent \& éparpillent derrière eux les poignées battues. Le Foin eft prefque fuffifanment fané après cette opération, fes feuilles font confervées, \& il fait encore un arfez bon fourage.

Cette dernicre méthode eft préférable aux deux premières, la feconde eft plus difpendieufe \& noins expéditive. Dans la première, il y a beaucoup de graines perdues, le fleau brife leurs enveloppes, elles ne font plus propres à la germination. Cette graine veut être fémée dans $f$ capfule, comme lamande dans 


$$
\text { DU SAIN-FOIN. }
$$

fon noyau. Le fleau, en outre, en détachant dans l'aire la graine du Sain-Foin, en extrait auff d'une multitude de mauvaifes plantes qui font tombées fous la faux avec lui. Il y a même une efpece de gramen connu des Laboureurs, fous le nom de Fenxfe; quand fa graine, qui a la forme d'une aiguille, fe trouve mêlée avec celle du Sain-Foin, il eft prefqu'impofible de l'en féparer. Il faut donc préférer la dernière de ces trois méthodes, fir tout lorfqu'on recueille la graine de la première récolte. Celle de la feconde poiffe n'étant pas fi abondante, \& les épis étant plus rares, il' paroît plus avantageux de les égraper fur pied.

Après la première coupe du SainFoin, l'ufage le plus ayantageux que lon puiffe faire de la feconde pouffe, eft de le faire pâturer. Cepen- 
$34 \quad C U L T U R E$ dant file temps permet d'en faucher une partie, il n'y faut pas manquer. 11 eft d'expérience, que le SainFoin mangé en verd fait àbonder le laitage, \& lui donne une qualité fu. périeure. Mais, comme on l'a déjà dit, c'eft le regain qu'il convient de donner aix Vaches pendant l'hiver.

Le Sain-Foin fourre le pâturage non-feulement des bêtes à cornes, mais encore des bêtes à laine. Cette propofition, contraire à l'opinion de plufieurs Cultivateurs qui regardent la dent dı mouton comme un poifon mortel pour cette plante, eft prouvée par quatre années confécutives d'expériences.

Dans l'hiver de 1760 à 1761 , on fit une première épreuve. On abandonna au troupeau un journal de Sain-Foin; la permiffion fut donnée jufqu'au premier de Février, parce 
qu'alors la féve commençant à entrer en mouvement, il eût été dan. gereux d'en interrompre le jeu. ( On fçait qu'il eft fouvent mortel pour un arbre de le dépouiller de fes fenilles pendant la première action de la féve.) Les premières impreffions du foleil ranimèrent les plantes, $8 x$ ce champ dans le mois de Mai fournit auffi abondamment que ceux qui $n^{2} a v o i e n t$ point été pâturés.

Enhardi par cette expérience, on n'héfita pas dans l'hiver de 1761 à '1762, de mettre en pâture pour le mêtme temps une prairie de plus de. trente journeaux. Au commencement de Février la neige couvrit la campagne jufqu'aul $x 2$ de Mars. Les troupeatix détenus dans les bergeries jettoient leurs Agneaux, les meres n’avoient point de lait, tout périffoit dans les Fermes voifines. Ceux 
j6.CU $L T U R E$

qui avoient pâturé le Sain-Foin; fortifiés par cette bonne nourriture, fupportèrent ce temps de détreffe; \& comme on avoit eu l'attention de ne livrer les femelles aux béliers qu'ał commencement d'Octobre, elles jettèrent en Avril des Agneaux forts \& vigourenx, qui naiffans avec lherbe tendre, fe trouvèrent tout d'un coup dans l'abondance. Cependant le jour tant defiré de la fonte des neiges étoit arrivé ; les SainFoins découverts offroient un tapis de verdure. Le Berger n'y put réfifter. Le jour même du dégel, il eut limprudence d'y conduire fon troupeau, pas une plante ne fut épargnée, le fol fut paitri dans toute fon étendue, tout fut bouleverfé. Il n'eft point ici queftion des regrets du Propriétaire : il eut la confolation d'appercevoir an bout de quelques 


\section{$D U S A I N-F O I N$.}

jours de nouvelles pouffes, les plantes s'élevèrent avec la plus grande vigueur, \& chaque journal, à la première coupe, lui donna plus de quatre milliers péfant de Foin fec. La même Prairie fut pâturée également dansl'hiver de 1762 à 1763 fans que 1a récolte en ait fouffert, \& dans l'hiver acuel 1764 , elle eft employée au même ufage.

Il feroit difficile fans doute de faire une épreuve plus complette du peu d'inconvenient qu'il y a à faire paître les bêtes à laine fur le SainFoin. Cependant comme les expériences en Agriculture véulent être répétées dans différens cantons \& fur diffèrentes natures de fols avant de faire foi, on penfe qu'il eft à propos de ne faire celle-ci qu'avec précalition, \& d'abord fur une petite étendue $: 2^{\circ}$, De refpecter les Sain-Foins 
$38 \quad C \cup L T U R$

dans les temps des pluies, dans la crainte de trop paîtrir \& de conroyer le fol: $3^{\circ}$. De s'abftenir abfolument de ceux qui font dans leur jeuneffe, pour leur donner le temps de fe piéter, jufqu'à l'âge de deux ans : $4^{\circ}$. De recommander aux Bergers de ne point fixer trop long-temps leurs troupeaux fur le même endroit, mais de leur faire parcourir la prairie pour les empêcher de brouter l'herbe de trop près: $5^{\circ}$. Enfin de leur en interdire abfolument l'entrée au commencement de Février.

Il n'eft pent-être pas inutile d'obferver, que fi l'on veut faire paitre les Vaches fur le Sain-Foin, il faut n'y laiffer aller les bêtes à laine que quand il n'y aura plus de quoi fournir aux premieres. Les bêtes à cornes ne peuvent manger après les moultons; ceux-ci laiffent une odeur fur 
le pâturage qui dégon̂te celles-lì. D'ailleurs les bêtes à cornes né dépouillent que l'herbe d'une certaine hauteur, \& le Mouton, à qui il ne faut qu'une herbe courte, trouve encore après elles de quoi fe nourrir abondamment.

Du Sain-Foin confidéré comme Denrée commercable.

ON vient d'obferver les avantages du Sain-Foin dans l'ufage qu'on en peut faire comme nourriture des animaux, confidérons-le à préfent comme denrée commerçable; calculons fon prodiut pendant le cours de fix années, par comparaifon à celui du Seigle, qui eft l'objet principal de la culture dans la haute Champagne, \& voyons fi la répugnance du Laboureur à facrifier quelques engrais à celle du Sain-Foin, eft fondée. 


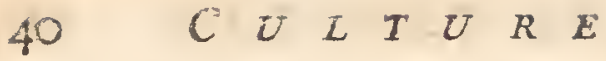

On fuppofe une terre bien pré parée, clargée d’amendemens fuffifans pour faire une bonne terre à Seigle. Un journal de dix clenrées de cette terre, fil'année eff favorable, pourra rendre un nombre de quinze gerbes de Seigle par denrée, ce qui fait dix nombres pour le joumal. Chaque nombre rendra trois boiffeaux \& demi de grain net à porter au marché ( ce produit ef̣t rare ). C'eft donc pour un journal trente-cinq boiffeaux ou quatre feptiers trois huitiémes, mefure de Chaalons, qui vendus à raifon de fix livres le feptier, donneront pour cette année, vingt-fix liv. cinq fols, liv. rol.

ci. .............26 5

La feconde année ce journal fera enfemencé en 


\section{$D U S A I N-F O I N . \quad 4 I$ liv. fol. \\ Ci-contre.....26 26}

Avoine; en eftimant fon produit aux deux tiers du Seigle, ce qui eft trop fort, on aura dix-fept livres dix fols, ci..... 17, I0 La troifiéme année le champ reftera en jachère $\&$ ne rapportera rien.. $\infty \infty$

4315 .

Total du produit des trois dernières années. $43 \quad 15$. Pour les trois années fuivantes, même produit.......... $43 \quad 15$.

Ainfi un journal de bonne

terre à Seigle aura rendu en fix ans "quatre-vingtfept livres dix fols, ci.. . 87 1०. 
$42 \quad C \quad U$ E T $U$ \& $E$ liv. fol.

Śi l'on eût mis ce même journal en Sain-Foin, il n'eût rien rendu la première année, en fuppofant les femailles faites en Printemps, ci........ $\infty \infty_{0}$.

La feconde année la première déponille eft de peu d'objet en l'évaluant feulement à fix cens liv. péfant de.Foin fec, à raifon de douze liv.le millier, fair fept liv. quatre fols, ci.......... 7 4.

La troifiéme les plantess'étănt fortifiées en duront donné deux milliers, ci. . 24.

La quatriéme le Sain-Foin dansfa force, (On fe fouvient qu'il a été dit dans le paragraphe précédent, 
DU SAIN-FOIN.

liv. rol.

que chaque journal avoit 314 rendu quatre milliers) on le réduit ici à deux mille cinq cens, ce qui fait trente livres, ci...... 30 . La cinquiéme, idem, trente livres, ci........ 30. La fixiéme, qui commence à dégénérer, deux milliers feulement, vingtquatre liv. ci....... 24.

Total du produit des fix années.......... II5 4:

On ne parle point de la feconde coupe qu'on aura dî faire chaque année, ou que l'on aura confommé en pâturage, ni de la graine qu'on aura recueillie. Or fe contente d'en faire compenfation avec les pailles

$\mathrm{D}$ ij 
de Seigle \& d'Avoine dont on n'a point parlé:

Or fuivant ce calcul, il eft évident que le rapport pécunaire du SainFoin furpaffe celui du Seigle \& de l'Avoine; que le premier n'a demandé que la préparation de trois labours avant celui des femailles, \& que les autres ont exigé les frais de denx labours, au moins, par chaque année; que le prix de la femence du Seigle \& de l'Avoine excéde de beaucoup le prix de la femence du Sain Foin, puifqu'on a femé qua. tre fois celles-ci contre une foisfeulement celle:la; que la terre qui a porté le Sain-Foin eft comme renouvellée an bout de fix années, \& aniéliorée pour rècevoir du Froment, \& pour une fuite de récoltes d'autres grains; \& que celle qui a porté du Seigle a commencé dès la première année à 
fe detériorer, \& fe reffent déjà de l'épuifement. Le6 frais de récolte font à peu près les mêmes; mais ceux de battage, de criblage, \& les foins qu'il faut prendre du Seigle dans le grenier, font tous à la charge de celui-là. Le Sain-Foin une fois dans la grange, tout eft dit.

Ce parallele n'a pas befoin quion s'y arrête. Loin d'être concluant en faveur de la répugnance du Labonreur, il détruit le préjugé qui l'a éloigné jufqu'à préfent d'établir des Prés Artificiels. Il n'a befoin que de calculer lui-même, d'après l'expofé qu'on vient de faire, pour en revenir facilement.

De la manière de défricher utilement le Sain-Foin.

LE dernier avantage à retirer du Sain-Foin eft, comme on l'a dit pré- 


\section{$46 \quad C U L T U R E$}

cédemment, d'améliorer le fol, \& de le préparer fans y mettre d'autre amendement, à porter du Froment immédiatement après que le SainFoin aura été défriché. Plufieurs Cultivateurs paroiffent encore douter de cette propriété, quoiqu'un fimple raifonnement fuffit pour les en convaincre. Mais on n'en donne point d'autre ici que l'expérience. On leur affirme qu'à la dernière récolte, 1763 , un champ de Sain-Foin défriché, contenant deux journeaux, fans avoir reçu d'amendement après le défrichement, a rendu 1455 gerbes de Froment. Ce Produit eft affez beau pour qu'on ne demande pas mieux;'on auroit peine àl'obtenir fur une terre bien fumée. Si donc quelques particuliers n'ont pas réuffi, on ne craint pas de dire, que c'eft qu'ils s'y font mal pris, \& que le défriche ment a été mal fait, 


\section{$D U S A I N-F O I N$.}

Il faut défricher le Sain-Foin dans l'Automne, il doit être retourné de façon que les racines foient tolites expofées à l'air. Les charrues ordinaires de la hante Champagne, appellées Bretauches, font mal cette opération, il faut des charrues plus fortes, telles à peu près que celles dont on fe fert dans la Brie, armées d'un coutre, \& dont le verfoir toit affez long pour culbuter toutes les plantes. Dans le courant de l'hiver on donnera un labour plus profond que le premier, vers le 15 Avril un troifiéme encore plus profond , \& vers le ro Mai on femera du Sara. fin * à raifon de quatre boiffeatix par journal, qu'on enterrera legère-

* Les deux journeaux, dont on a rapporté plus haut le produit, navoient point reçla de Sarafin, le Froment y avoit eté femé far le. fimple déftichement. 
ment à la charrue. Lorfqu'il fera en pleine fleur, on le coupera avec la faux, \& le lendemain on fera marcher la charrue pour l'enfouir, comme l'on fait le fumier. La terre en cet état, on l'enfemencera en Froment dans les dix derniers jours de Septembre. On pourra s'affurer d'une récolte abondante \& fupérieure en qualité à celle qui auroit été faite fur des fumiers.

L'Ouvrage intitulé, Le Gentilhomme Cultivateur, indique une pratique qui rentre dans celle-ci, en fubftituant les turneps ou gros navets au Sarafin, \& en les faifant paitre par les moutons avant de femer le Froment. On conçoit toute l'efficacité de cette méthode; les turneps en groffiffans ont la faculté de divifer \& d'ameublir le fol; \& après avoir été mangés fur pied, ce qui en refte. 


\section{DU SAIN-FOIN:}

y pourrit \& y laiffe un véritable engrais. Mais les turneps font fujets à manquer dans les terreins crayeux de la haute Champagne, fur tout in le temps eft déterminé à la féchereffe. En conféquence la graine eft rare, \& il faut la changer au moins tous les troisans; parce que fans cela le fruit dégénére. Le Sarafin abonde, \& l'amendement qu'il met dans le foly étant enfoui, n'eft pas moins réel que celui qu’y laiffent les turneps. Les verdages enfouis font tous également propres à ameublir la terre. Enfin on garentit cette méthode par le réfultat de plufieurs expérien. ces qui ont toutes été heureufes.

$\mathrm{Au}$ furplus ce ne font point des nouveautés que l'on propofe, ce n'eft point un fyftême favori qu'on veut accréditer. L'Agriculture eft un Art trop effentiel \& trop né; 
jo $C U E T U R E$

ceffaire pour ofer entreprendre de l'aftujettir aux caprices de la mode ou de l'imagination; c'eft une pratique ancienne qu'on cherche à faire revivre pour le bien de l'humanité; pratique recommandée dans les plus anciens Ecrits fur la culture des terres, \& 2 qui rendroit la Province de Champagne méconnoiffable, fi elle y étoit fiuvie généralement.

Quelle différence feroit-ce en effet pour le Laboureur de voir à la tête de fa baffe-cour bien peuplée, une femme œconome occuper fes enfans du foin de fes beftiaux, préparer des engrais abondans pour améliorer fes champs, enrichir les marchés du produit de fes étables \& de fa laiterie, \& rapporter dans fa famille l'aifance \& la gayeté; ou de 1a voir trainant après elle une Vache décharnée dans des champs dépour- 


\section{DU SAIN-FOIN: SI}

vus de toute fubfiftance, perdre; ainfi que fes enfans, des journées entières à lui ramaffer quelques touffes d'herbes fades ou quelques mauvais feuillages, \& de ne rentrer chez elle qu'accablée de mifére \& d'ennui.

Quelle différence pour le Labou: reur de fortir dès le lever de l'Aurore avec des Chevaux vigoureux, d'approfondir des fillons en chantant, de s'applaudir de fon ouvrage, \& de calculer d'avance les produits de fa récolte; ou de pouffer devant lui une bête exténuée, de partager fes efforts pour laiffer à peine une foible trace dans fes champs, de fuc: comber fous le poids de la fatigue; \& de défefpérer du fruit de fon tra: vail.

Etabliffons des Près Artificiels ces triftes tableaux difparoiffent, nos

$\mathrm{E}$ ij 


\section{CULTURE}

plaines s'embelliffent, le Voyageur étonné ne s'y reconnoît plus, la Province s'honore, \& la mifere en s'enfuyant des campagnes, entraine avec elle ces honteufes paffions qu'elle enfante, l'envie \& la mauvaife foi.

Mais, dira-t-on, les petits Laboureurs dans les plaines de Champagne font pauvres; la terre, il eft vrai, ne leur manque pas, mais ils manquent à la terre par le défaut de facultés, \& la graine de Sain-Foin eft d'autant plus chère, qu'il faut la femer avec abondance, $\&$ en proportion double de ce que l'on feme en froment; c'eftà-dire, environ un boiffeau, mefure de Chaalons, par denrée, \& il faut qu'ils fe déterminent à en femer une certaine quantité pour pouvoir reffentir les avantages dont vous les flattéz ? C'eft ici le cas d'inviter les 
Propriétaires des fermes de travailler pour leurs pauvres Fermiers \& pour eux-mêmes. Il n'y a point de Propriétaire qui n'ait un intérêt fenfible à l'amélioration de fon domaine, \& ce fera un bienfait qui tournera à fon avantage, de donner à fon Fermier, lorfqu'il ne feroit pas en état d'en faire la dépenfe, la graine néceffaire pour former le premier établiffement.

Le même motif d'un intérêt légitime doit engager Meffieurs les Décimateurs à la même charité, qui n'eft pas moins digne du zèle des Seigneurs, pour foulager la mifere de leurs Vaffaux.

Mais ces actes de bienfaifance do:vent être faits avec une fage difcrétion pour que l'objet foit rempli. il ne fuffit pas de donner, il fant lien donner. Ils doivent done renfermer

E iij 
$\$ 4 C U L T U R E$

de la part du Laboureur, l'obliga tion d'augmenter tous les ans fa Prairie, au moins pendant les quatre premières années, \& d'en juftifier, ou de payer le prix de la graine qu'on lui aura donnée fous cette condition. Au bout de ce terme, inftruit par lui-même de l'utilité de cet établiffement, il n'eft point à craindre qu'il le détruife, il trouvera trop d'avantage à remplacer par de nouveaux femis les défrichemens qu'il commencera à la fin de la cinquiéme année. C'eft alors qu'une plus grande étendue de terre qu'à l'ordinaire; préparée pour recevoir du Froment, augmentera fes produits, \& payera avec ufure le fruit de fes travaux.

A l'égard des Propriétaires des Fermes, la chofe eft trop intéreffante pour eux pour qu'ils n'en faffent pas une claufe expreffe dans 
leurs baux qui obligera leurs Fer. miers à mettre tous les ans une certaine étendue de terrein en Pré Artificiel.

\section{De la Graine de Sain-Foin.}

ON ne doit point finir ce Mémoire fans prévenir les Cultivateurs du foin quils doivent apporter au choix de la graine de Sain-Foin. Elle eft fujette à tromper, \& il eft néceffaire de s'affurer de fa fécondité avantd'en faire ufage.

La première attention confifte à ne recueillir cette graine que lorfqu'elle eft meure, ce qui fe reconnoit lorfque les premiers grains de l'épi ont pris une couleur jaunâtre, quoique ceux de la pointe foient encore verds. Si l'on attendoit plus longtemps, elle meuriroit trop, \& le moindre vent occafionneroit une 


\section{CULTUR है}

perte que l'opération de la faux trì pleroit.

La feconde eft de ne point récolter la graine des plantes qui ont déja fix à fept années; l'expérience apprend qu'il y en a beaucoup d'infidéle. On ne confeille pas non plus de laiffer meurir celle qui croit fur les plantes qui n'ont encore qu'une année, cela les fatigue trop, \& l'on a vu des champs périr pour leur avoir laiffé porter graine jufqu'à la maturité dans cette première jeuneffe. Du moins on n'a pu attribuer qu'à cela la perte qu'on a foufferte. C'eft fur des plans de deux, trois \& quatre ans que l'on peut être afiuré de recueillir la meilleure graine.

On croit s'être apperçu, que lorfqu'elle eft recueillie, la pluie qui tombe deffins lui fair du tort : ainfi il faut en faire la récolte par un temps 
fec, l'enlever de deffus les draps à mefure qu'elle eft battue, la porter dans l'air de la grange pour la vanner tout de fuite, l'étendre auffi-tôt dans un grenier \& la remuer quatre à cinq fois par jour pendant quinze jours; après quoi, fi elle paroît entièrement féche, on peut la mettre en tas. Cette graine nouvelle eft très-fijjette à s'échauffer, elle fermente vivement, fa couleur devient noire \& le germe périt. On fe rappelle cependant qu'il y a quelques années, il en fut oublié pendant deux ou trois jours dans le grenier où elle avoit été dépofée au fortir de la grange. L'odeur aigre qui s'y répendit, avertit qu'elle y étoit, on la remua beaucoup \& fouvent, on l'étendit dans un grand efpace jufqu'à ce qu'elle fût entièrement rafraîchie, la couleur refta noire, mais on la 


\section{CULTURE DU SAIN-FOIN:}

fema au Printemps, elle leva fort bien.

Cependant comme il arrive encore, malgré toutes les attentions qu'on recommande, que l'on foit trompé, c'eft une précaution fage de faire effai de fa graine avant que d'enfemencer fon champ, \& d'en mettre un nombre déterminé dans la terre. On verra fi la totalité leve, ou feulement une partie, \& l'on fe réglera là-deffus pour diriger la quantité de femence qu'on devra mettre en proportion des graines qui au: ront levé.

$$
\text { FI } N_{6}
$$

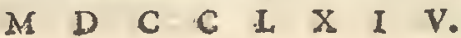





\section{$\mathrm{L} A \mathrm{R} \mathrm{T}$ \\ DE C U.L T I V ER}

焉要

LES POIRIERS,

ET DE FAIRE DES CIDRES Selon l'u age de la Normandie. Par M. le Marquis de Chambray.

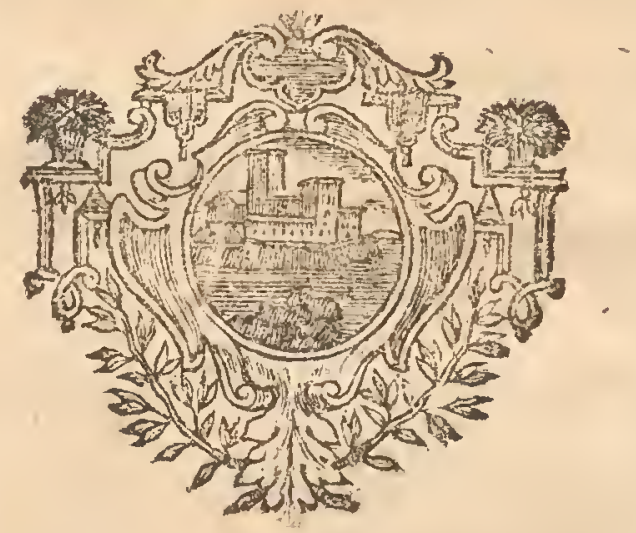

A PAR I S,

Chez GANEA U rue Saint-Séverin, près-l'Eglife s aux arnes de Dombes \& à Saint-Louis

M. DCC. LXV. AVEC PERMISSIOV. 


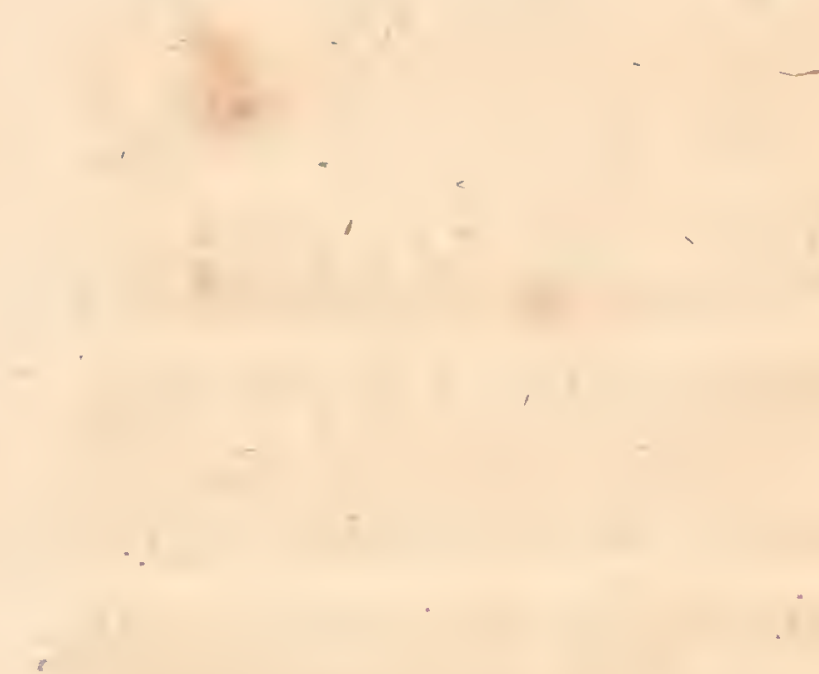

I

ㄴ.

s.

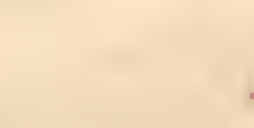


;

\section{$P R E F A C E$.}

ON ne doit pas s'attendre à trouver dans cet Ouvrage, l'élégance \& les graces d'un beau ftile. La matiere que j’ai choifie n'en eft gueres fufceptible. Le coloris des fleurs que le pommier nous offre, fe répand difficilement fur un difcours qui en traite, $\&$ les échos de la campagne ne peuvent répéter que des fons champêtres. C'eft pour les Agricoles que j'écris, j'efpere qu'ils voudront bien fe contenter d'un détail exact, d'une expreffión claire, de la vérité de mes préceptes, \& 
de la certitude de mes expé riences. J'ai tâché de réunir ces qualités fi néceffaires à un ouvrage purement didactique. Je ne préfente ici que le réfultat des réflexions, \& des épreuves journalieres que jai faites; jaloux d'être utile aux Cultivateurs, j'ai fouvent épié la Nature, je l'ai furprife quelquefois dans fes opérations; heureux fi mon travail peut contribuer au bonheur de mes femblables, l'humanité coninoit-elle un. plaifir plus doux \& plus touchant? 


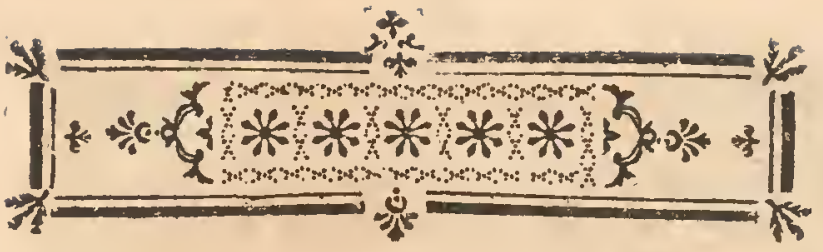

\section{$L^{\prime} A R T$}

DE CULTIVER

LES POMMIERS,

LES POIR IER S,

ET DE FAIRE DES CIDRES

Selon l'ufage de la Normandie.

\section{INTRODUCTION.}

勧 affez nouvelle pour la France, Son ufage a paffé d'Afrique en Efpagne, \& d'Elpagne en Nor- 
mandie. Les habitans de cette Province, qui ne trouvoient pas le climat \& le fol de leur pays propres à la culture des vignes, n'en avoient que pour fe procurer une boiffon néceffaire, mais pcu agréable; beaucoup de canronsen étoient privés totalcment, par la froideur \& l'humidité des terres; les peuples qui les habitoient, étoient réduits à l'ufage de la biere ou à celui de l'eau. La fréquentation des Normands avec les Bifcayens par le commerce maritime, leur fir connốtre l'utilité du cidre; ilsplanterent des pommiers, apporterent de Bifcaye, des greffes de ces fruits à cidre, \& les premieres pommes qu'ils recucillirent, furene appellées pommes de Bifcait ". 
nom que les pommes conferven encore. Bientôt les pommiers fe multiplierent, \& l'ufage du cidre devint général. Alors on abandonna, les vignes Normandes: il n'eft refté aux différents terreins fur lefquels elles éroient plantées, que le nom que le Flant leur avoit donné, le clos de la. vignze. Il y a à-peu-près trois fie-. cles que les vigncs ont été détruites en Normandie, \& que les pommiers ont pris leur place. Les Bretons, tes Anglois ont fuivi l'exemple des Normands, \& par la culture des pommiers fe font procuré une boiffon aufi agréable qu'utile : on commence même dans différentes Provinces de la France, \& furtout en Picardie, à cultiver cet arbre avec 


\section{4}

fuccès, \& à préparer des cidres qui ne font pas fans mérite; mais fouvent auffi ces cidres manquent de qualité, \& e e'eft moins à celle du fol qu'il faut s'en prendre, qu'au défaut de choix dans les efpeces de pommes, \& au peu d'intelligence de ceux qui préparent cette boiffon. C'eft pour remédicr à ce double inconvénient qu'on fe détermine à rendre pur: blic ce petit ouvrage.

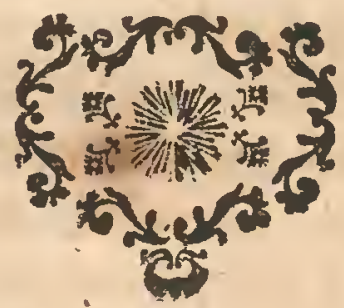




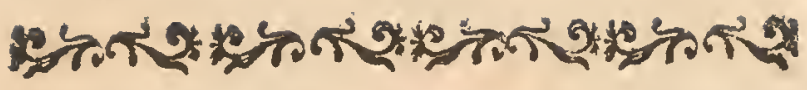

C H A P I TRE I.

De la Pepiniere.

II $\mathrm{L}$ y a des cantons dans la Normandie, comme le pays de Bray, celui de Caux, \& plufieurs autres, où les habitans fe font un revenu confidérable des pepins qu'ils fement \& qu'ils vendent au bout de deux ans. Ils ont alors deux pieds de haut. Si on peut fe procurer de ce plant, c'eft le moyen le plus prompe \& le plus facile pour établir une pepiniere. Si on nele peut pas, il faut, dans le tems que les pommes font pilées, faire ramaffer dans leur marc des pepins de pommes à $\mathrm{ci}$. dre, ceux des pommes à couteau ne produiroient pas le même effer. On préparera dans fon jardin un terrein bien meuble, on 


\section{6}

y femera le pepin dans le mois de Février; on aura foin de le bien farcler pendant les deux années qứil reftera dans la terre, de crainte que les mauvaifes herbes ne nuifent à fon accroiffement. Au bout de deux ans, on le levera pour en former la pepiniere.

Il faur choifir pour la pepiniere un terrein neuf, s'il eft poffible, ou tout autre terrein qui foit en bon état de culture, dont le fond ne foit poine argilleux. On le défoncera de dix-huitpouces de profondeur; \&z s'il y a du gazon fur la fuperficie, on le précipitera dans le fond de la tranchée: quand le terrein fera fuffifamment labouré. \& dreffé à la bêche, \&r non à la charrue, ou fi la terre étoit trop dure pour fe fervir de la bêchẹ, au pic \& à la pelle, on placera le plant au cordeau, chaque fujet 'à neuf 
pouces de diftance. Les rangs fe: ront éloignés les uns des autrés de deux pieds \& demi. Quand on pilante plus ferré la pepiniere n'en vient pas mietix. Cette plantation fe fera dans le cours de lhiver; après quoi on couvrira toutc la pepiniere de vieux chat1me, ou de feuilles qu'on ramaffera dans lcs bois; cctte couverture tiendra les racincs fraîches, la terre meuble, \& empêchera lés mauvaifes herbes de pouffer. Si on couvre fuffifamment la pepiniere, elle n'aura befoin d'aucune culture; fi elle n'eft pas affez couverte, les mauvaifes herbes paroîtront au bout de quèlque tems. Alors avec la houe plate, il faudrä gratter la fuperficie de la pepiniere pour détruire les herbes; ces herbes détruires \& féchées par le foleil, augmenteront l'ancienne couverture de chaume ou des feuilles qui au- 


\section{8}

ront été mifes d'abord fur la pepiniere. Au bout de deux ans on coupera toute la pèpiniere par le pied, les nouveaux jets qu'elle donnera furpafferont bientôt les anciens. S'il en pouffe plufieurs ¿̀ chaque pied, on les arrachera, pour ne laiffer que celui qui fera de la plus belle efpérance. On ne coupera rien à ces nouveaux jets pendant deux ans: il fuffira d'arracher les rejettons qui paroîtront à leurs pieds, \& d'entretenir la pepiniere bien nettc fans y fouffrir d'herbes. Au bout de deur ans, la pepiniere en ayant quatre de plantation, on commencera à couper les branches gourmandes de chaque fujet, obfervant de ne pas dégarnir le pied \& le corps de l'arbre des petites branches, parce qu'elles empêchent la feve de fe porter avec trop de vivacité vers le haut de l'arbre, ce qui le fait groflir du pied \& 


\section{9}

croître en forme de cierge : c'elt la perfection d'un arbre de pepiniere.

A la cinquieme \& fixieme année, on arrêtera tous les arbres qui feront bons à lever l'année fuivante; dette opération confifte a leur couper la tête environ a fix ou fept pieds de hauteur, felon la difpofition naturelle de l'arbre. Il fe formera enfuite une tête à l'arbre, dont les branches auront cinq à fix pouces de longueur; \& l'année d'après on commencera à lever les fujets qui auront le plus de force, les autres en viendront mieux. Il y a beaucoup de cantons dans la Normandie, où l'ufage eft de greffer les arbres dans la pepiniere; cela ne feroit pas convenable pour ces fujets vigoureux qu'on leve dès la fixieme année, \& qui fone l'élite deilla pepiniere; mais lorfque ces plantes hâtives 
font enlevées, \& placées dans les champs, on peut avec fuccès greffer les fujets qui font par leur groffeur en érat de fupporrer la greffe. L'avantage qu'on en retire eft, que fi la greffe manque, l'arbre fait une nouvelle tête dans la pepiniere avec plus de facilité que dans les champs; \& que lorfqu'on ne plante dans les champs que des arbres dont la greffe eft bien reprife \& bien recouverte, on jouit plus promptement du fruit de fa plantation: on n'eft pas exporé à tous les accidens qui arrivente aux greffes qu'on met dans lés champs, fur des arbres qui $\ddot{y}$ ont été plantés fans greffer; le vent, les oifeanx les caffent, elles meurent parce que la féve de l'année n'eft pas toujours bonne; elles effuyent mille au: tres accidents, qui mettent le propriétaire dans le cas d'arra- 
cher de jeunes arbres pour y en fubftituer d'autres, de façon que dans une plantation de pommiers, il s'en trouve fouvent un tiers qui a été changé d'année en année, d'où il arrive qu'il y en a qui prennent de l'âge \& de l'accroiffement, tandis que les autres font à leur premiere ou à leur feconde année de plantation. Cela ne fait jamais un bon effer ; car les premiers planrés qui, n'ayant point eu d'accident, ont pouffé avec vivacité, étenda leur branches \& leurs racines, fe font, pour ainfi dire, emparés du terrein, $\&$ les dernicrs arrivés ont bien de la peine a fe frayer une place. On évite ces inconvenients, en formant tu plant de fujets dont la greffe eft bien affurée dans la pepiniere.

Les arbres qui font dans la pcpiniere, ou qu'on a tranfpor- 
tés dans les champs fans greffer ; portent fouvent du fruit avant que d'être greffés. Si ce fruite eft gros, doux, ou amer-doux, qu'il ait du jus, une chair blanche ou jaune, qu'il ne foit point aigre, on confervera l'arbre fans le greffer, ce fera une nouvelle efpece de pommes à cidre : elles ne fe font multipliées à l'infini que de cette maniere; comme les œuillets de graine donnent des fleurs nouvelles qui font les plus eftimées des curieux. C'eft pourquoi on a dit qu'il ne falloit femer que des pepins de bonnes pommes à cidre; ceux des pommes de rainette ou d'autres pom. mes à couteau, ne produiroient que des fruits aigres peu propres pour le cidre, au lieu que les arbres qui provienuent d'un pepin de pomme à cidre, donnent Couvent un fruit d'excellente qualité. 


\section{3}

On finira ce chapitre par avertir qu'il faut que la pepiniere foit bien claufe, pour la garantir des beftiaux, \& par exhorter le cultivateur à la tenir couverte de feuilles le plus qu'il lui fera poffible; rien n'eft fi analogue à un arbre que les feuilles d'un arbre quelconque. Ce petit foin n'eft pas difpendieux; des femmes ramaffent au rateau, fous des futayes ou des taillis, des feuilles lorfqu'elles font tombées, \& les portent fur la pepiniere quand. clle eft finie. 


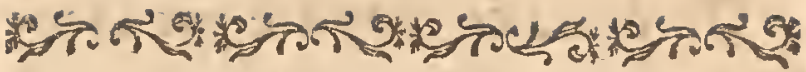

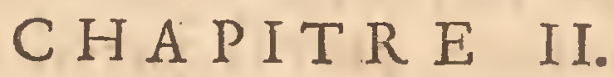

Maniere de former les plants, lorfque les arbres font bons à lever dans la pepiniere.

$\mathbb{I}$

Es terreins qui n'ont qu'une légere fuperficie de terre friable, dont le fond n'eft qu'une argille dure, ne conviennent point aux plants de pommiers. Les racines des arbres ne peuvent s'infinuer dans cette terre trop denfe ; on a beau faire des trous larges \& profonds, les remplir de terre meuble, de gazons, l'arbre croît \& paroît beatu pendant quelques années; mais lorfque les racines ont atteint la rcrre argilleule, il ne croît plus; il fe couvre de mouffe \& il meurt peu-à-peu fans donner de fruit. Il en eft de même des terres qui 
1.5.

n'ont fous la fuperficic friable; que de la craie, du tuf blanc: mais dans toutes lesterres fortes $\&$ graffes qui ont du fond, dans tous les graviers qu'on nomme creux, parce qu'ils font faciles à remuer à deux \& trois pieds de profondeur; dans toutes les terres mêlées de petits grès plats $\& x$ caffants, les pommiers viennent à merveille. La terre rouge \& humide convient mieux aux poiriers qu'aux pommiers; il fant toujours en avoir un tiers fur fa terre, pour fournir aux Domeftiques \& anx Journaliers, de la boiffón lorfque les pommes manquent. Rarement les pommiers rapportent du fruit trois ans dé fuite; quand les pommes. manquent, les poires font ordinairement abondantes.

Il y a beaucoup de perfonnes qui plantent des ceintures de pommiers \& de poiriers autour dé 


\section{6}

leurs terres labourables; cet ufage a un grand inconvénient. Lorfque les charretiers labourent, ils ne rencontrent pour l'ordinaire, que trois arbres à chaque bout du champ dans leur journée; le propriétaire ne peut leur donner du monde pour aider à paffer ces arbres, \& renverfer la charrue, à leur approche, les hommes deftinés à certe emploi n'auroient pas une occupation fuffifante; les arbres au bout des champs font donc écorchés à tous les labours, \&x finiffent par périr. C'eft pourquoi il eft bien plus convenable de choifir les terres graveleufes qu'on polféde, pour y former des plants, dans toute leur étendue; parce que les jours qu'on y laboure, on fait accompagner le charretier par une ou deux perfonnes, qui renverfent la charrue à l'approche de l'arbre \& qui la remettent à fa place quand 
quand l'arbre eft paffé. Le charretier laboure de fuite toutes les rangées d'arbres, après quoi il renvoie les hommes qui l'one aidé, \& travaille feul dans l'intérieur des rangécs.

Dans bien des pays il fe trouve plus de terres légeres que de terres fortes; il n'eft pas à propos de couvrir celles-ci d'arbres fruitiers, qui, en ombrageant le bled l'empêchent d'être aufli ferme dans fa paille, aufi nourri dans. fon grain. On convient que l'avoine vient pour le moins aufi belle fous les pommiers qu'en plein champ. Mais le bled n'a pas le même avantage; \& c'eft ce qui doit fixer l'attention du cultivateur. Il faut donc dans les cantons ou la bonne terre eft rare, ne planter que les terres légeres; les arbres en les ombrageant un peu, défendront le grain des ardeurs du foleil, il n'en 
fera que meilleur; au lieu qute dans les terres fortes, le grain ne veut pas être ombragé ; fouvent il verfe fous les pommiers.

On ne peut dire précifement quelle efpece de terrein donnera le meilleur cidre; l'expérience feule peut inftruire à cet égard: les fonds les plus gras de la Normandie, le Cotentin où eft Ifigny, le pays d'Auge, donnent des cidres excellents. L ces enclos de la Commanderie de Saint-Vaubours près de Rouen, oì le terrein eft fort mauvais, produifent un cidre admirable quia un bouquet unique. Prefigny dans le Vexin Normand, Chambray fur la riviere d'Iton fi renommés pour l'agrément de leurs cidres, n'ont qu'un terrein léger \& picrreux. Ainfi ce n'elt que par l'expérience qu'on connoîtra la valeur du fol. Mais il faut toujours sattacher aux efpeces de pom- 
mes les plus renommées, cár elles contribuent beaucoup à la bonté du cidre.

Lorfqu'on aura deftiné un terrein pour y mettre des pommiers; au commencement de l'automné, on fera des trous carrés de quatre pieds d'ouverture en tous fens, $\&$ de deux pieds de profondeur. L'ouvrier fera trois lots de la terre qu'il en tirera : le premier, de la fuperficie qui eft ameublie par la culture, ou par les engrais naturels, comme feuilles \& gazon, fi ce n'eft pas en champ labouré qu'on travaille: le fecond, de la terre qui fe trouve au-deffous de celle qui a été cultivée: le troifieme, des pierres qui fortiront de chaque trou. Les trous feront placés au champ labouré à trente-fix pieds de diftance fur tous fens; par ce moyen les plants ne couvriront pas trop la terre, les racines trouveront 


\section{0}

à s'étendre fans fe renconerer; auront une fubftance fuffifante, l'arbre viendra promptement, aura une écorce vive \& claire, $\&$ rapportera beaucoup de fruit. Il y a encore d'autres avantages à éloigner ainfr les plants, les terres font moins ombragécs, les grains y viennent mieus, les charretiers qui trouvent une diftance de trente-fix pieds d'un arbrè̀ l'autre, peuvent faire rentrer leurs chevaux dans la direction de la ligne qu'ils tenoient pour tracer leur fillon, \& qu'ils n'ont quittée que pour éviter le picd de l'arbre \& ne pas toncher à fon tronc, de façon que prefque tout le terrein fe trouvant labouré par la charrue, il ne refte à cultiver à la hone que la terre du pied de larbre, que la charrue a laiffée fans culture en forme de navette, dont chaque pointe cft tournée vers l'arbre précédent 
* le fuivant. Si la charrue nie pouvoit reprendre ainfi la direction de fon fillon, après avoir tourné fur chaque côté des arbres, on feroir obligé de laiffer à chaque rangée d'arbres une planche de terre fans la labourer; ce qui donneroit un ouvrage immenfe pour mettre une fi valte étendue de terrein en labour avec la houe fourchue; on ne peut donc trop recommander de mettre une diftance fuffifante. d'un arbre à un autre; quoique bien des propriétaires n'ayent pas cette attention. Il eft vrai que les plants que l'on met dans les. cours ou autres terreins qui ne fe cultivent pas à la charrue, ne doivent pas être fir éloignés:; quinze pieds de diftance d'un arbre à l'autre fuffiront. Lorfque les trous font faits \& difpofés, ainft qu'on viene de le marquer, on arrache dans la pepiniere, 
les arbres qui font en bon état $\&$ dont les tailles des années pré. cédentes font bien recouvertes; en obfervant de leur laiffer le plus de racines \& de chevelu qu'il eft poffible; on les taille en bec de flutte, l'entaille pardeflous; on rafraîchit les branches de la tête de l'arbre, fi elles ont trop pouffé dans la pepiniere depuis que l'arbre a été arrêté; enfuite on jette dans le trou la première terre qui eni a été ôtée; on fait encore tomber dedans, la terre la plus meuble qui fe trouve aux environs; on la range horifontalement avec la fourche ou la bêche; on pofe l'arbre deffus, un homme le tient droir, un autre couvre les racines de la meilleure terre qu'il peut trouver à fa proximité ; quand elles fone couvertes, on fecoure un peu l'arbre en ligne perpendiculaire, pour que la terre mouvante qu'on 
vient de jetter fur les racines; sinfinue par-tout. Après quoi on recouvre en totalité le pied de l'arbre de la terre quil'environne; on la butte en forme de navette, fi e’eft dans les champs labourés; \&x fi c'eft ailleurs, en forme de baffin qui doit avoir comme la premicre ouverture quatre pieds de diametre; ce baffin fera rond, l'arbre doit être dans le centre du cercle; les bords anrone un pied d'élevation fur le niveau dur terrein, le baffin ira toujours en baiffant vers le pied de l'arbre, afin qu'il puiffe recevoir les caux du Ciel qui doivent humedter les racincs. S'il refte après cela des picres fur les bords des trous, on les fair porter dans les chemins les plus proches pour les. réparer. C'eft un très-bon ufage de jetter au fond des trous, avane que d'y mettre ancune terre, des. joncs marins, des genêts, bruye- 


\section{4}

res, gazons chevelus, ou autres broflailles quand on peut en avoir, cela tient la terre creufe $\&$ meuble, les racines s'en trouvent très-bien; mais généralement il faut planter fur la fuperficie de la terre, c'eft-à-dire, le moins profondement qu'il eft poffible; les arbres qui font encaiffés trop avant, languiffent prefque toujours \& ont beaucoup de mouffe; leurs racines ne pouvant percer le fond, \& les parties latérales destrous, font contraintes de remonter pour s'étendre fur la fuperficie de la terre, cela arrête totalement le progrés de l'arbre. Il eft vrai que les arbres plantés trop ì fleur de terre, fort plus facilement renverfés par les vents; mais il vaut mieux perdre quelques pommiers par cet accident, que de voir languir routes les plantations.

Dès la premiere année, Ia 


\section{5}

tête des pommiers nouveaux plan. tés pouffe de petites branches \& des feuilles; au bout de trois ans elle eft affez confidérable, pour qu'on puiffe commencer à greffer les fujets qui marquent affez de vigueur pour recevoir la greffe. Cette vigueur dépend de la façon dont les racines ont travaillé. Il y a toujours des arbres qui font plus lents à pouffer en racines ; alors la tête étant moins garnie, on différe à les greffer. Si on greffoit avant que l'arbre cût bien pouffé en racines, la greffe feroit languiffante, ou mourroit; mais lorfque l'arbre affectione le terrein, qu'on voit qu'il poufle une tête bien garnie de branches, que l'écorce en eft vive \& 2 tranfparente, il teit tems de pofer la greffe. Il faut grefier quand le champ eft enfemencé en bled, parce que dans cette annéc \& $!_{2}$ fuivante, qu'il produit des avoi. 


\section{6}

nes, les moutons approchent plus rarement desarbres; car il faut obferver que leur odeur nuit à la feve. Quand les arbres font greffés ils ne reçoivent de culture que par les labours. Le Cultivateur fait remucr la terre de leur pied avec la houe fourchue à toutes les failons de bled, mars, \& gueret, \& jetter de la femence au pied, quand les champs font entemencés. Les pommiers fe plaifene beaucoup plus dans les terres labourables que dans les enclos: $1^{\circ}$. Parce qu'en ouvrant la terre qui couvre leurs racines, elles reçoivent le bénéfice des infuences de l'air. $z^{\circ}$. Parce qu'en répendant des fumiers dans les champs, on augmente lcur vigueur. Cependant dans les cours des maitairies, où il y a un grand concours de beftiaux qui rependent des engrais, les arbres viennent très-bien \& rapportent beamcoup, parce qu'ils 


\section{7}

lont ordinairement à l'abri des vents par quelques murs ou bâtiments, ce qui conferve les fleurs. Mais dans les pâtures éloignées des maifons, fi elles n'ont pas un bon fonds, fi les arbres ne font pas cultivés tous les ans, en les bêchant au pied, en grattant la mouffe, en dégarniflant les branches de leur fuperfiu, ils languiffent \& rapportent peu. En général on connoît que l'arbre fe plaît dans un terrein, lorfque l'écorce en eft vive 8s claire, qu'il y a peu de mouffe autour des branches; \& dans tous les pays qui produifent des pommicrs de cette nature, on peut y établir des plants à cidres avec une forte de confiance; aurefte, il n'y a que l'expérience qui apprenne file cidre aura de la qualité. J'ai vî de très-beaux pommiers dans les montagnes de Savoic;j'ai envoyé au Marquis d'On- 
28

cieu d'excellentes greffes de Normandie qui ont bien réuffi ; il y a lieu de croire que le cidrequi en proviendra fera bon, \& je fuis perfuadé, que beaucoup de pays pourroient fe procurer l'ufage du cidre, fi les Cultivateurs vouloient en tenter l'établifrement.

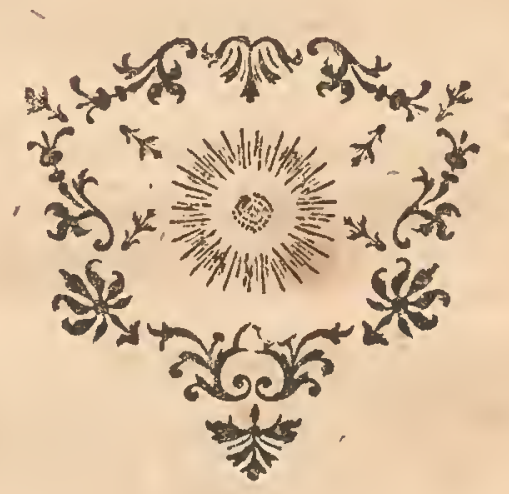




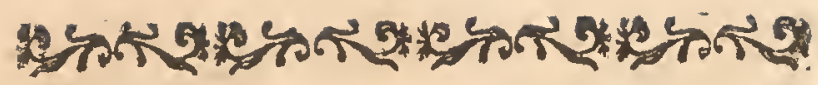

\section{H A P I T R E III.}

\section{De la Greffe。}

L ORSQUe les pommiers font en état de recevoir la greffe, on en prend dans les fommités des branches des pouffes de l'année; fi on n'a pas chez foi de bonnes efpeces, on en fait venir de Normandie, en s'adreffant à quelqu'un capable de faire un bon affortiment, bien varié; les greffes peuvent être cueillies deux mois avant que de les employer; on les envoie dans de la mouffe frấche; on les met en terre dans un coin du jardin quand on les a reçûes, \& on en fait ufage quand le tems y eft propre; celui qui les envoie à foin de mettre une étiquette à chaque efpece différente. A la fin d'Avril, \& même

C iij 
un peu plutôt pour les efpeces précoces, on commence à greffer par un tems doux \& fans pluie. On taille les greffes de la longueur de fix à fept pouces; il importe peu que l'œuilleton de la greffe foit coupé, puifque d'une feule pouffe de l'année', on en fait fouvent deux greffes. On forme au bout de chaque greffe, un efpece de coin d'un pouce de long en applatiffant les deux côtés fans toucher à la moëlle de la greffe, excepté dans l'extrémité de la taille ou elle fe trouve découverte; on coupe la tête de l'arbre avec la fcie, à cinq pieds $\&$ demi ou fix pieds de terre; on pare avec la ferpette la partie qui a été fciée; on fend l'arbre en deux autant qu'il eft néceffaire pour $y$ introduire la greffe ; on le tient entrouvert avec un coin de bois; on pofe deux greffes fur chaque côté de 


\section{I}

Ia fente de cet arbre; on fait rencontrer exactement de chaque côré, l'écorce de la greffe \& celle de l'arbre. On retire le coin, l'arbre ferre auffitôt les greffes. Alors on environne cette tête d'arbre ainfi greffée, avec une bande de papier; on fait une poupée avec de la filafle tirée en long, \& garnie de rerre franche réduite en mortier; on pafte cette filafle entre les deux greffes, pour que tout y foit plein \& garni de cette efpece de mortier. On la fait tourner plufieurs fois autour de la tête greffée, cela forme une poupée grofle comme le poing, au travers de la quelle fortent les deux greffes, qui paroiffent de la longueur de cinq pouces au travers de la poupée; enfuite on lie au corps de l'arbre, une petite bianche feche, qui paffe un peu au-deffus des deux greffes, pour empêcher les oi- 


\section{2}

feaux de fe repofer deflus \& de les caffer. On met deux greffes, parce que fi l'une manque l'autre peur ne pas manquer. Il n'eft pas avantageux qu'il en refte deux fur un arbre; ces deux greffes qui ne s'uniffent jamais parfaitement, laiffent toujours un vuide entr'elles; lorfqu'elles font chargées de fruits \& qu'il furvient des vents, l'une des deux greffes fe caffe \& entraine avec elle la moitié de l'arbre qui s'éclate en deux ; pour parer à cet inconvénient, lorfque les deux greffes ont bien pouffé, on choifit la plus belle, \& d'un coup de maillet, on fait fauter l'autre avec un cifeau de menuifier; on met fur cette coupure, de la terre franche délayée ; \& la greffe qui refte, ne tarde pas à s'emparer de la totalité de l'arbre, le tout fe recouvre $\&$ s'unit en peu de tems. Bien des gens ne prennent pas tousces. 


\section{3}

foins, auffi ont ils des arbres de mauvaife mine, tortus, trainants jufqu'à terre, plantés fans aucune fimétric; il n'en coûte pas davantage de donner de la grâce atix chofes utiles. Lorfque les branches de la greffe en croîffant tombent trop bas vers la terre, il faut avoir foin de les couper \& de les diriger de façon qu'elles puiflent laiffer un libre paffage aux chevaux de harnois, pour la culture des terres labourables fur lefquelles les arbres font plantés; il elt même très-convenable de ne greffer dans les terres labourables, que des elpeces dont le bois s'éleve, \& a la forme de l'oranger, car les branches trainantes font incommodes au Cultivateur; l'arbre à hautes branches eft plus agréable à la vue. Il y a de fi bonnes efpeces de fruits dans ce genre, qu'il eft facile d'avoir des cidres excellents 


\section{4}

en ne fe fervant pas des arbres dont les branches s'inclinent trop vers la terre, \&z qui font toujours expofés à l'attaque des beftiaux. Lorfque les greffes meurent, il faut donner le tems à l'arbre de faire une nouvelle tête, on la coupe enfuite comme on avoit fair la premiere fois, obfervant de couper jufqu'à ce qu'on trouve le bois parfaitement vif, \& fans aucune impreffion de l'ancienne cicatrice; fi ces fecondes greffes manquent encore, il faut arracher l'arbre \& en planter un autre. Tout le monde fçait que le pommier en fleur \& même lorfqu'il eft chargé de fruits, eft un très-bel arbre.

\section{此造:}




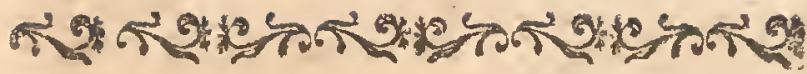

\section{H A P I R E IV.}

Des différentes efpeces de pommes à cidre.

$\mathrm{O}_{\mathrm{N}}$ doir divifer les pommes en trois claffes; les précoces qui font mûres au commencement du mois d'Août ; ces fruits font d'une grande utilité, ils procurent des cidres à ceux dont la récolte précédente à manqué; fouvent on les attend avec impatience; le cidre en eft léger \& agréable ; on en boit ordinairement à la foire de Guibray qui commence le 9 Août. Ces pommes font :

L'A mbrette.

Le Renouvellet.

La Bellefille.

Le Jaunet.

Le Blanc. 
I1 eft convenable de les greffer dans un même canton, pour avoir plus de facilité à les cueillir, fans être obligé de parcourir tous les plants.

La dcuxieme claffe, que l'on cueille à la fin de Septembre\&. au commencement d'Octobre eft :

Le Frefquin.

La Girouette.

La Haute-branche.

Le Long-bois.

L'Avoine.

Le Gros-adam-blanc.

Le Doux-évêque.

Le Rouget.

L'Ecarlatte.

Le Blanc-mollet.

Le Bedan.

Le Petit-masoir.

Le Saint-George.

Le Gros-amer-doux.

Le Petit-amer-doux.

Marie-la-douce. 
La troifieme claffe eft mûre à la fin d'Octobre; les meilleures font :

La Peau-de-vache.

L'Alouerte-rouffe

L'Alouette-blanche.

La Cofte.

Le Blagny.

Le Blase-duré.

L'Adam.

Le Doux-reté.

Le Mattois.

Le Pepir.

Le Doux-verer.

Le Clofente.

La Rouffe.

La Reinette-douce,

Marie-honfroy:

Le Rambouiller.

Le Pied-de-Cheval.

Le Gros-coq.

L'Equieulé.

L'Epicés 


\section{8}

L'Ante-au-gros.

Le Bon-vallet.

Le Saint -Bazile.

Le Mufcadet.

L'Amer-mouffe.

Le Petit-moulin-⿳亠丷-vent.

La Petite-chappe.

Le Rebois.

Le Grout.

La Germaine.

La Sange.

Il y a une infinité d'autres efpeces de pommes en Normandie. La même pomme a auffi trèsfouvent divers noms felon les divers cantons, mais il s'en forme tous les jours de nouvelles par efpeces doubles qui viennent dans les pepinieres, \& qui font d'une excellonte qualité; elles multiplicroient bien plus fi on laiffoit rapporter tous les jeunes arbres avant que de leur couper la tête ; on fait fouvent de grandes 
injultices dans cette cxécution, on détruit des fruits admirables; il en eft des pommes comme des fleurs qu'on feme, la graine produit beaucoup de fimples \& peu de double. Les pommes fimples font petites, aigres, ont peu de fuc, la chair verte. Les doubles font groffes, blanches ou colorées, ont la chair jaune ou blanche, font douces ou amei-douces, \& certaincment ces efpeces nouvelles en valent bien d'autres. Il eft vrai qu'on prétend que les pommiers qui n'ont pas été greffés, rapportent plus rarement que les autres, mais j'ai l'expérience du contraire; il y a même de ces arbres qui produifent plus fouvent \& plus abondamment que les autres, conme auffi il peut s'en trouver qui ne foient pas chanceux, alors on les grefferoit fur les branches : mais lorfqu'un arbre non greffé produit de bon 
$\&$ beau fruit $\&$ en produit fouvent, il faut le conferver, puifqu'il eft plus vigourenx 'qu'un autre, dure plus long-tems \&z n'eft pas fi fujet à être caffé par les vents.

Ceux qui ne voudront pas faire ufage de cette remarque, trouveront dans les liftes qu'on a don. nées, des efpeces plus que fuffifantes pour établir d'excellentes plantations d'arbres à cidre. Il y a un grand avantage, à greffer des trois claffes de pommes cideffus indiquées, car il vient fouvent des gelées dans le printems qui font périr les fleurs; fi ce moment arrive dans le tems que les efpeces précoces font en fleur, on a lieu d'efpérer que la fleuraion des deux claffes fuivantes fera plus heureufe; fi au contraire les gelées ou les vents-roux arrivent tard, les efpeces hâtives ont dejà leur fruit formé, \& il n'y a que 


\section{1}

pommes tardives qui en fouffrent. Enfin on fentira de refte, qu'on doit plus compter fur des arbres qui ne fleuriflent pas dans le même-tems, que fur ceux quifleuriffent tous enfemble; av ec ceux-ci on a tout, ou rien; avec les autres on a toujours quelque chofe, \& prefque jamais une abondance générale, fouvent à charge au propriétaire qui n'a pas affez de futailles, pour metre tous les cidres que les arbres ont produit. Les vents-roux chaffent avec eux un brouillard qui a plus l'air d'une légere fumée, que d'un brouillard lordinaire; toutes les fleurs des arbres qui en font frappées, font roties dans l'inftant, \& fe pulvérifent enfuite comme des feuilles de tabac. Les fleurs qui n'en font pas totalement détruites, produifent unc petite pomme dans laquelle il s'érablic un ver, \& qui tombe avant 


\section{2}

qu'elle ait pris un accroiffement confidérable.

Il y a des perfonnes, qui, pour garantir les fleurs de leurs arbres de ce vent deftructeur, affemblené au couchant de leurs plants de diftance en diftance, de petits tas d'herbes feches, de feuilles, de bruyeres, \&xc. \& quand ce vent qui vient toujours du couchant commence à fouffler, elles mettent le feu à ces petits monceaux de maticres combuttibles, la fumée qui en fort eft portée par le vent vers le plant, corrompt le mauvais air, \&x garantit les fleurs d'une deftruction certaine; cela n'eft pas bien difficile à pratiquer; car en fuppofant qu'on ait pas eu Ia précaution d'affembler des matieres combutibles au couchant des plants, il eft encore tems d'y en porter lorfque le vent-roux paroît; il faut peu de matiere pour produire beaucoup de fu- 


\section{3}

mée, on a bien-tôt raffemblé chez-foi de vieux foins pourris, de petites bourrées de bois, fur lefquelles on jette un peu de paille monillée, les vents-roux difparoiffent promptement, \& ne durent jamais trois jours; d'ailleurs ils font fans effet pendant la nuit, il réfulte auffi de ces vents des chenilles en quantité. Lorfqu'elles fe font emparées des arbres, il n'y a d'autre fecret pour s'en défaire, que d'écheniller; on fe fert peur cette opération d'une efpece de cifeanx qu'on enmanche à un bâton; ils reftent ouverts par le moyen d'un reffort, comme les cifeaux dont on fe fert pour couper les ongles des pieds. On fait mouvoir la paltie fupéricure de ces cifeaux; par le moyen d'une ficelle qui y eft attachée, \&z on coupe la branche au.deffous de l'endroit ou les chenilles font établies : c'elt 


\section{4}

toujours fur les petites branches. Si on n'a pas ces cifeaux, on peut fe fervir du croiflant du Jardi. nier, \& brûler enfuite les branches qui feront tombées à terre avec la coque des chenilles. On peut faire fous les arbres pluficurs fumigations pour faire périr les chenilles, mais elles ne font pas fans inconvenient. Il eft plus court d'écheniller, cela n'eft pas fi long; fans cette précaution, il ne refte pas une feuille aux arbres, les chenilles les dévorent \& altérent confidérablement la féve.

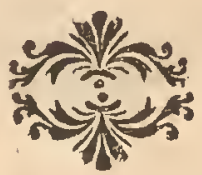




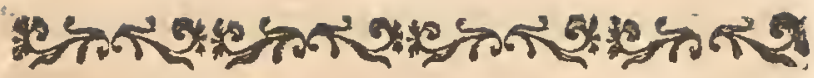

CHA PIRRE V.

De la maniere de cueillir les: Pommes.

$S_{\text {I les plants font enclos de }}$ haies out de follés, de façon qu'on puiffe les défendre de l'approche des beftiaux, la meilleure façon eft de laiffer meurir les pommes à l'arbre, au point que la plus grande partic tombe d'elle-même, après quoi en fecouant les branches des arbres, le refte tombe fans efforr. Par ce moyen l'arbre n'eft point battu avec des gaules, le bourgeon qui doit produire l'année fuivante n'eft point détruit, les arbres rapportent plus fouvent \& davantage. On laiffe ces pommes fous les arbres, elles y meuriffent $\&$ lorfque le tout eft tombé, foit na- 


\section{6}

turellement, foit parles fecouffes qu'on a données aux branches; on pofe les pommes à terre dans des bâtiments, pour les piler lorfqu'elles font à leur vrai point de maturité. Ce qui eft enfentiel pour avoir de bons cidres. Il ne faut jamais tranfporter les pommes dans les bâtimens, lorfqu'elles font mouillées par la pluic ou par la rofée, cela les fair noircir, pourrir , \& ôte la qualité des cidres. Pour les pommes qui ont meuri fur les arbres, fielles font à leur point jufte, on peut les porter tout de fuite fous la roue du preffoir. Il faut avoir foin de ne pas mêler dans les bâtimens les pommes avancées, avec les tardives, les unes feroient trop mûres \& même pourries, que les autres feroient encore vertes; il n'en réfulteroit qu'un jus imparfait. On a done foin de ne porter dans chaque grenier, que 


\section{7}

les pommes qui font de la mêine. claffe, \&r qui doivent être pilées dans le même-tems; quant à celles qui fe trouvent dans les terres labourables, \& qui font expofées aux beftiaux, on envoie tous les matins pendant les mois de Seprembre \& d'OAtobre, ramaffer ce qui eft tombé pendant le nuit. On les pile de bonne-heure pour en faire de petit cidre, car la plûpart fon verreufes; quand le fruit de ces arbres eft fuffifamment mur, on en fait la cucillette générale, en fecouant \& gaulant les branches pour faire tomber le fruit. C'eft alors qu'il y a bien du bois de brifé \& que l'arbre fouffre ; mais il eft impolfible de parer cet inconvenient. Les pommes ainfi cuieillies, on les porte dans les bâtiments qui lcur font deftinés : on peur même les mettre fur l'herbe dans un lieu fermé proche le preffoir, elles y meu- 


\section{8}

riront bien, l'air ne les endoma: gera pas ni les pluies : il n'y auroit à craindre qu'une gelée trop forte, une pomme gelée ne donne jamais de bon cidre. On s'en garantira fi on les couvre de feuilles; la pomme fe conferve parfaitement fous les feuilles. On ne doit piler les pommes que quand elles font bien mûres, on le connoît à leur couleur jaune, à la bonne odeur qu'elles rependent quand quelques-unes commencent à pourrir. C'eft-là ce qui indique leur vrai degré de maturité. 


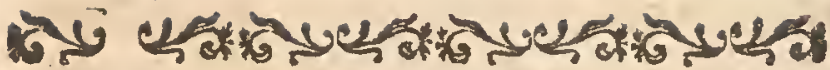

\section{H A P T RE VI.}

\section{De la façondes Cidres.}

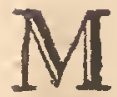

onsieur des Pommiers dans fon livre intitulé : L'art de $s$ 'enrichir promptement par l'agriculture, nous dit, "que les pom"mes d'un doux-amer, quelque"unes un peu aigres font les feu" les propres à donner de bons "cidres ". Cet affortiffement n'eft pointencore venu à la connoiffance des Normands, qui n'eftiment que le doux \& amerdoux, \& qui regardent les pommes un peu aigres, comme contraires à la bonne qualité du cidre. Monfieur des Pommiers écrit bien, a du zele. Ses eflais fur les cidres font encore nouveaux, il les perfectionnera tous les jours. Si je ne craignois pas de miécar- 
so

ter de mon fujet, je lui propoferois mes objections fur la culture du fainfoin ; je prends feulement la liberté de lui repréfenter, que les fuccès quil a eus dans fon pays pour l'établiffement des fainfoins, ne feroient pas les mệmes. dans la haute-Normandie, dans le Perche, partout oì les terres saffaifent \& fe condenfent beaus coup. Ce n'eft point à la graine qu'il rient ; les Fermiers qui cultivent une de mes terres près de Falaife, qui ont des fainfoins en abondance, m’ont apporté de la graine la plus parfaite, $\&$ font venus la femer dans la terre de Chambray que j'habite, fituée entre Verneuil au Perche \& Nonancourt,; les labours, les fumiers, rien n'a été épargné; le fạinfoin a très-bien levé; mais lạ terre s'eft affaiffée pendant l'été, la plante s'eft trouvée enfermée comme dans une brique cuite au. 


\section{1}

folcil, \& eft morte peu-à-peu. Bien d'autresque moi ont manqué leurs expériences dans ce canton, qui eft plein de pierres à fufifl $8 Z !$ de gros gravier rouge ou gris. Il faut donc dire avec l'excellent. Autcur du Mémoire Sur la culture' du Jainfoin dans la haute Champagne, que le plus grand fecret pour avoir des fainfoins, eft. d'empếcher l'affaiffement des terres, c'eft à quoi je travaille actuellement; jc rendrai compte au public de mon procédé fi je. réuffis. On me pardonnera cette digreffion en faveur de mon zele pour le bien public.

Quand on veut faire du cidre parfait, lorfque les pommes font àleur point de maturité, à mefure qu'on les prend fur la pelle de bois pour les mettre dans la corbeille \& les porter dans les auges du preffoir, une ou detrx femmes, ôtent toutes les pommes noires \& pour- 


\section{2}

ries, on les garde pour les mettre dans le repilage: mais comme tout le monde ne veut pas faire certe petite dépenfe, voicil'ufage ordinąire pour biẹn pile les fruits. Jedis bien piler parce que les trois quarts des Normands ont des cidres troubles \& de mạvais goût, par le peu de foin qu'ils donnent a. les façonner. Je ne donnerai point les dimenfions d'un prefroir ; elles font affez connues,

Le cheval qui fert au pilage, ayant fuffifamment fait tourner la meule de bois ou de piẹre qui fert à écrafer les pommes, on les porce ainfi écrafées fur le tablicr du preffoir; elles y font dreffées en forme carrée; on met un rang de paille entre chaque couche de pommes pilées; la bouts de la paille excédent de quatre doits, le carré cube de pommes écrarées, qui eft dreffé par le conducteur des cidres, fur le tablief 
du preffoir. Plus on exhauffe cet édifice, plus le jus coule en abondance fur le tablier, \& tombe dans la cuve appellée beflon. Lorfque ce cube, qu'on appelle la motte, eft à la hauteur d'environ quatre pieds, que le cidre n'en découle plus, on met deffus un carré de plançhes fortes, jointes enfemble, qui excéde les bords dc cette motte de trois pouces de toutes parts; enfuite on met de petits foliveaux de même grandeur fur ce carré de planches, \& on defcend par le moyen d'une vis, l'arbre à preffoir fur tout l'édifice. Son poids fait fortir le jus dès pommes écrafées, il tombe dans le beflon; alors fi on n'a pas de cuvcs, on tranfporte le cidre du beflon dans des futailles bien nettes \& bien reliées: mais fi on a la commodité d'avoir dans fon preffoir des cuves contenant 2 , 4,6 , queues plus ou moins, on 


\section{4}

jette dans ces cuves tout le cidre qui forr du beflon; il y refte trois à quatre jours fans monter, au bout defquels il fermente trèsfort. Toute la lie monte comme l'aîne du vin; quand on voit que cette croûte commence à s'abaiffer, il eft tems de tirer le cidre \& de le porter dans les futailles. On a une groffe canelle de bois ou de cuivre au bas de la cuve, on emplit les fceaux par cette canelle, on porte le cidre dans les tonnealix qui font préparés fur les chantiers dans la cave. Par ce moyen il ne fe trouve point dans la futaille, cette affreufe quantité de lie dont les cidres des Payfans font toujours furchargés, le cidre ne s'aigrit pas fi promptement, eft plus clair, \& a plus belle couleur. Si les cidres par la nature du tererin ne font pas fuffilamment colorés, ce qui arrive fouvent, il faut laiffer $\mathbf{m} \hat{a}$ - 


\section{is}

quer les pommes pilées pendart quelques houris, c'eft-à-dire, differer d'en faire fortir le jus après qu'clles font pilées; par cetre méthode on donne au cidre autane de couleur quion le juge à propos. Quand les tonneaux font pleins, il faut les lauffer fans les bonder pendant trois fenaines, pour leur donner le tems de bouillir \& de jetter par le trou de la bonde, une quantité d'impuretés; le cidre ayant celfé de bouillir, on remplit lestonncaux avec d'autre cidre, $\&$ on bonde; mais il faut regarder fouvent aux futailles pourleur donner de l'aic sil eft befoin, car fouvent le cidre fait fauter lescercles, furcout. fi on a bondé trop tôt. Les Parifiens ne trouvent jamais le cidre affez doux; fi on veut en avoir qui conferve fa douceur très-long-tems, qui mouffe $b$ en, \& qui ait une très-belle coticur, 


\section{$\$ 6$}

il faut mettre plein un grand chaudron de fer ou de cuivre, contenant à-peu près troisfceaux de cidre fortant du beflon, le faire bouillir fans interruption depuis le matin jufqu'au foir, enforte quil fe reduife en fyrop épais; lorfque ce fyrop eft à-peuprès à fon degré de cuiffon, on y jette une demie-livre de beau miel, on le fait encore bouillir un peu, \& l'on jette le fyrop par le trou de la bonde d'une pipe qui contient cinq cent pintes. On la roule fur tous fens, on entonne dedans le cidre fortant de la cuve, au bout de très-peu de tems on a du cidre très-clarifié, très-doux, piquant \& agréable. Cette recette eft encore meilleure pour des cidres qui n'ont pas beaucoup dé qualité par eux-mêmes: elle feroit très inutile à Ifigny $\&$ en bien d'autres endroits de la Normandie. Ce fyrop fe garde, fi on 


\section{7}

veut, dans des pots très-longtems, il y refte en confiltence de miel, \& quand on veut en faire ufage dans les rhumes, il faut le battre avec de l'eau chaude; il eft très.bon pour la poitrine.

Si le cidre n'éclairciffoit pas dans les tomneaux, ce qui arrive quelquefois, furtout à ceux qui ont des pommes dont le jus eft gras \& limoneux; il faudroit pour une demie queue de deux cent cinquante pintes, broyer un pain de blanc d'Efpagne, autrement craie de Briançon, y joindre le poids de deux liards de fouphre en poudre, jetter le tout dans la futaille par la bonde, remuer le cidre avec un bâton fendu en quatre; il fera bientôt clair fin , c'eft la maniere de le coler. Au mois de Mars on mer en bouteille le cidre qu'on deftine pour la table des Maîtres, en obfervant de ne le boucher à demeure 


\section{$5^{8}$}

qu'au bout de quelques jours, atitrement il cafferoit bien desboutteilles : ce cidre mouffe, pique le palais, porte aut nés, monte à la tête, plaît beatucoup ' mais ce ne feroir pas une boiffon convenable pour l'ordinaire, elle a trop de violence; les Normands boivent $\mathrm{ra}$ tement du cidre fans eau; il faut done voir l'ufage journalier qu'on peut faire du cidre.

Pour avoir une boiffon agréable \& faine ; il faut mettre quelque feaux d'cau dans les auges du preffoir en pilant les pommes, on regle cela felon le degré de force qu'on veut donner au cidre, lorfqu'il eft ainfi tempéré, il eft très-fain, on le digere facilement; on l'appelle la tifane des Normands. Mais ce cidre mêlé d'eau ne paffe gueres l'année, il s'aigric à la fin, au lieu que du cidre d'un bon crû, fe conferve mieux \& eft fouvent très-potable au bout de fix \& fept ans. 
*

C H A P I T R VII.

\section{Des petits Cidres.}

$S_{\text {I on buvoit le cidre pur à fon }}$ ordinaire, ce feroit comme fi on ne mettoit jamais d'eat dans fon vin. Il n'eft point de boiffon plus legere \& plus rafraîchiffante que le petir cidre, il n'a aucun des inconvenients des gros cidres, qui fouvent gonflent \& nourriffent trop; mais il faut que le petit cidre foit bien fait. Pour y parvenir, voici comment on doir procéder.

Le gros cidre êtant tiré du marc des pommes pilées, on exhauffe l'arbre à prefloir. On ôte de deffus la motte, les pieces de bois, \& le couvercle de planches qui y éroient. On releve le marc des pommes par couches, qui font 


\section{0}

marquées par les lits de paille qui feparent chaque couche de marc. On met le màrc dans une futaille défoncée par un bout, dans un coin du rablier du preffoir, \& dans les auges à piler. Si on a befoin de pepin pour femer, c'eft dans ce moment qu'on les met à part. On jette de l'eau fur le marc qui eft dans les auges \& quand il eft imbibé, on attele le cheval à la meule pour le repiler. Lorfqu'il eit futfifamment repilé, on le porteà pelletées fur le tablier du prefroir ; \& $z$ de ce repilage, on forme une nouvelle motte, comme on a fait pour le gros cidre. C'eft exactement le même procédé, pour dreffer la motte, mettre l'arbre à preffoir, porter du beflon dans la cuve, ou dans la futaille, fi on ne veur pas faire cuver le petit cidre, ce qui cependant le rendroit meilleur, \& le debarrafleroit de 12 


\section{$6:$}

plus grande partie de fa lie. Pour f̧̧avoir la quantité d'eau qu'il faut mettre fur le marc, la regle eft d'y en mettre autant qu'on en a tiré de gros cidre. C'eft-là la boiffon des Domeftiques : ij on veut qu'elle ferve aux Maîtres ou qu'elle foir d'une qualité plus forte, on jette dans le repilage quelques pelleréesd e pommes. Mais il y a une autre façon de faire du cidre mitoyen pour les Maîtres, \& c'eft la plus convenable ; elle confifte à jetter 2 , 3's ou 4 feaux d'eau dans chaque pilée de pommes, lorfqu'clles font bien écrafées, \& à faire enfuite tourner la meule pour que le tout s'incorpore. Plus le rour du preffoir eft grand, plus il contient de boiffeaux de pommes, ainfi on ne peur déterminer combien on mertra de feaux d'eau à la pilée; le Proprietaire en jugera facilcment il y a même 


\section{2}

des crî́s qui ont moins de qua-: lité , le jus des pommes eft moins fpiritueux, dans ce cas-là il faudroit moins d'cau. Chacun doit' connoître la valeur des chofes dont il fait ufage; le cidre mitoyen fe façonne comme le gros cidre ; il ne différe que par l'eau' qu'on y met, pour rendre cette boiffon plus convenable d la fanté ; les enfans qui en boivent font frais comme des rofes; ell $\mathrm{e}^{i}$ nourrit \& raffraîchit.

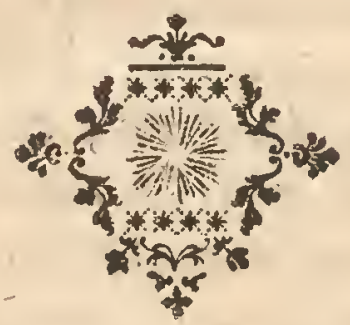




\section{3}

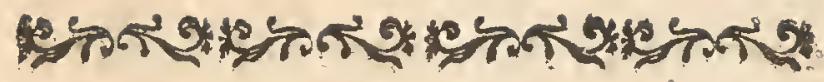

\section{CAHPITRE VIII,}

Des Poiriers, des. Poires, $\mathcal{E}_{\text {du }}$ Poiré.

I E poirier fe cultive de la même maniere que le pommier; les cidres de: poires fe font de même que ceux de pommes, mais le poirier veut une terre plus forte \&z plus humide que le pommier. Il faut effayer fon ter-: rein pour connoître celui qui lui: conyient le mieux, fi on plante ailleurs qu'en Normandie, oi ces chofes font connues de tout le monde. Le poirier fe plaît dans les terres cultivées, mais il ne craint pas tant que le pommier, celles qui ne le-font pas; il dure un plus grand nombre d'années: fon jus fupplée à celui de la pomme : en y mettant de l'eau. 


\section{4}

il fert de boiffon au peuple, comme on l'a expliqué ci-deffus à l'arricle des perits cidres Le poiré fans eau eft doux \& agréable, il fe garde deux ans: on prétend qu'il eft mal fain, il ne caufe cependant aucuns mauvais effets en Normandie, au contraire les Nourrices en boivent pour fe procurer une abondance de lait. Si on a fuffifamment de cidres de pommes, pour fon ufage \& la conformmation de fa maifon; on ne fair que du poiré fans eau, on en repile le marc avec de l'eau pour ne rien perdre; c'elt la boiffon des Domeftiques \& Journaliers. Les poirés fans eaux fe ven. dent bien dans les pays vignobles, lorfqu'on n'en eft pas éloigné, parce que cetre liqueur reffemble au vin; les Vinaigriers les achetent pour en faire des vinaigres qu'ils colorent avec la graine de fureau, \& les font paf- 


\section{5}

fer pour du vinaigre de vin; ceft un des gros commerces de la ville de Dreux. Quand on n'a pas ces débouchers pour le poiré, on le fair brûler comme les cidres de pommes, pour en tirer des caux-de-vie, qui font d'un très-grand ufage"en Normandie. L'eau-de-vie de poiré eft plus lympide \& plus vive que celle de pommé.

Il y a beaucoup de choix dans les greffes des poiriers; car il y a des efpeces de poires à cidre bien fupericures en qualité; lośs meilleures font :

L'Ecuyer.

Le Jacob.

Le Rouiilard;

Le Gros-melnil.

Le Rouge.viguy.

Le Blin.

Le Bois-prieur.

Le Huchet-gris. 


\section{6}

Le Huchet-blanc.

Le Verd.

Et plufieurs autres qu'il feroit inutile d'indiquer.

Ceux quivoudront fe procurer des greffes de pommes $\&$ de poires, pourront s'adrefler, en affranchiffant leurs lettres, à Monfieur le Marquis de Chambray, en fon château de Chambray, près Tillieres, route de Bretagne : il a des meilleures efpeces en tout genre, \& fe fair un plaifir d'être urile au progrès de l'Agriculture.

\section{FIN.}




\section{APPROBATION.}

J 'A I lû par ordre de Monfeigneur le Vice--Chancelier, l'Art de cultiver les Pommiers \& Poiriers,

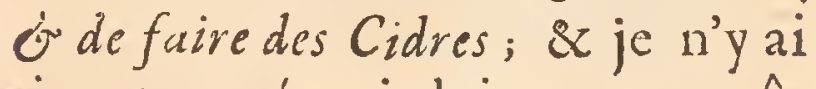
rien trouvé qui doive en empêcher l'impreffion. A Paris ce I 2 Juin 1765 .

\section{AMEILHON.}









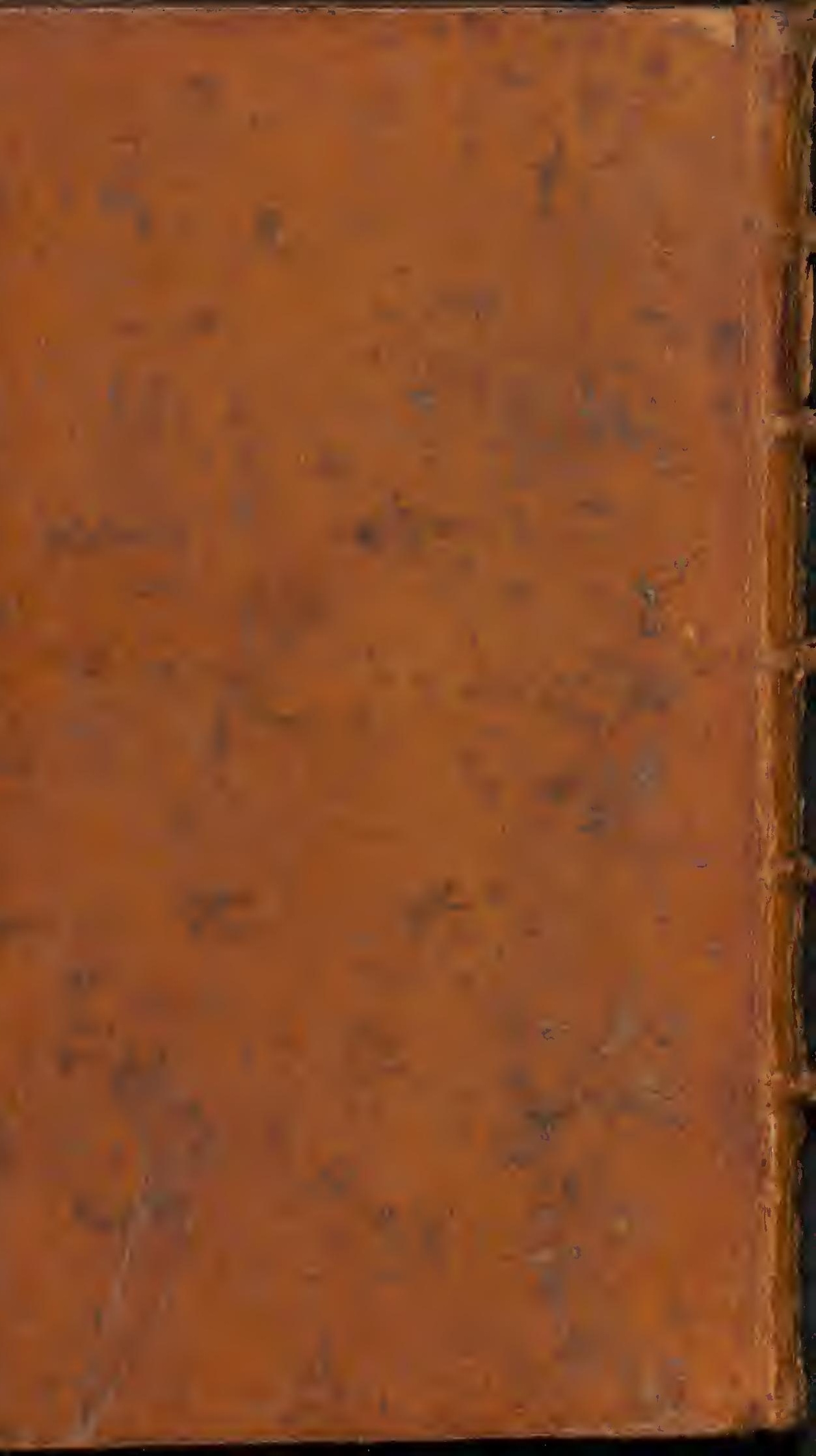

